\title{
Línea Base Situacional de la Ayuda para el Comercio en Guatemala y Honduras ${ }^{1}$
}

\author{
Kendall Ariana López Peña* \\ Ingrid Yerleyn Arroyo Hurtado** \\ Cristel Avendaño Quesada*** \\ Yoselin de los Ángeles Ramírez Bravo***
}

\begin{abstract}
Resumen
Este artículo pretende explicar el monitoreo de la Ayuda para el Comercio en los países más vulnerables de la región de Centroamérica, Guatemala y Honduras, durante el período 2007 al 201. Para esto, el trabajo analiza información cuantitativa que delinee el estado situacional de la Ayuda para el Comercio en sus cuatro dimensiones: 1. Financiación del desarrollo, 2. Costos del comercio, 3. Indicadores comerciales, y 4. Indicadores de desarrollo. Lo anterior, con el propósito de mejorar en el futuro los procesos de gestión de la ayuda en la región de Centroamérica, específicamente en Guatemala y Honduras, así como la toma de decisiones tanto para la OMC como para los donantes y receptores.
\end{abstract}

Palabras claves: Ayuda para el Comercio, línea base, Guatemala, Honduras

\begin{abstract}
This article aims to explain the monitoring of Aid for Trade in the most vulnerable countries of the Central American region, Guatemala and Honduras, during the period 2007 to 2019. For this purpose, it analyzes quantitative information that outlines the situation of Aid for Trade in the four AFT dimensions: 1. Development financing, 2. Trade costs, 3. Trade indicators, and 4. Development indicators. The foregoing, with the purpose of improving the future aid management processes in the Central American region, specifically in Guatemala and Honduras, as well as decision-making for both the WTO and donors and recipients.
\end{abstract}

Keywords: Aid for Trade, baseline, Guatemala, Honduras

\footnotetext{
${ }^{1}$ Este artículo es una versión revisada y ampliada del Seminario de investigación titulado "Estado de la Ayuda para el Comercio en el Sector Servicios, periodo 2007-2019: El Caso de Guatemala y Honduras" presentado por estas autoras en la Universidad Nacional, Costa Rica. Es parte del proyecto "Fortalecimiento de las capacidades teóricas y prácticas relacionadas con el Sistema Multilateral de Comercio" de la Universidad Nacional, Costa Rica.

* Doctorante del Programa de Estudios de Desarrollo Global. Universidad Autónoma de Baja California, México. Kendall.lopez@uabc.edu.mx Recibido: 12 de agosto de 2020; modificaciones: 09 de junio de 2021; aceptado: 15 de juli ode 2021. ** Licenciada en Negocios y Comercio Internacional. Universidad Nacional, Costa Rica. verleyn10@gmail.com

*** Licenciada en Negocios y Comercio Internacional. Universidad Nacional, Costa Rica. cristel.avendano.quesada@est.una.ac.cr

${ }^{* * * *}$ Licenciada en Negocios y Comercio Internacional. Universidad Nacional, Costa Rica. yoselin.ramirez.bravo@est.una.ac.cr
} 
Kendall López - Ingrid Arroyo - Cristel Avendaño - Yoselin Ramírez

Línea Base Situacional de la Ayuda para el Comercio en Guatemala y Honduras

\section{Introducción}

La Ayuda para el Comercio (AFT por sus siglas en inglés) es una iniciativa de la Organización Mundial del Comercio (OMC) que nace en la Conferencia Ministerial de Hong Kong en 2005 y que parte de la premisa de que no todos los países tienen la misma capacidad comercial para insertarse en el sistema multilateral. De este modo, promueve la movilización de recursos entre receptores y donantes; a través de la asistencia técnica y económica, que impulsen el desarrollo del comercio internacional.

Los países de la región de Centroamérica se han sumado a la lista de países que han utilizado al comercio internacional como mecanismo para alcanzar el desarrollo. Sin embargo, pese a las dificultades tras el cese de los conflictos armados en la década de los noventa, la región ha incorporado estrategias de apertura comercial y modernización de sectores productivos; que también han evidenciado la existencia de otras dificultades en cuanto a su infraestructura y capacidad comercial.

Este artículo busca generar una línea base situacional, que sirva como insumo para futuras investigaciones sobre la iniciativa de AFT en la región de Centroamérica, así como la forma en que esta se distribuye o destina a las áreas más vulnerables, con el objetivo de dar una perspectiva dinámica sobre el desarrollo de estos países centroamericanos. Asimismo, entendiendo que la mayoría de los estudios y los desembolsos de AFT se dirigen mayormente a los países menos adelantados (PMA), en particular los países africanos, este estudio constituye un acercamiento académico al análisis de esta iniciativa multilateral para los países de la región de Centroamérica.

Para el logro de este objetivo, el apartado metodológico contempla variables e indicadores, propios de las categorías de la iniciativa Ayuda para el Comercio de la OMC. Se trata de una línea base situacional que recopila información cuantitativa de los Exámenes Globales de Ayuda para el Comercio, específicamente en los países Guatemala y Honduras durante el período 2007-2019, la cual permite construir y analizar bases de datos de AFT para dichos países. De este modo, la presente investigación pretende dar respuesta a las siguientes interrogantes: ¿cuál es el estado situacional de la Ayuda para el Comercio en los países centroamericanos, Honduras y Guatemala? Y ¿cuáles son las áreas en las que se enfoca esta iniciativa en dichos países?

El documento se estructura en tres secciones. La primera sección, se analizan aspectos teóricos de la cooperación internacional y la Ayuda para el Comercio. En la segunda sección, se presenta la metodología propuesta. En el tercer apartado se analizan los resultados del estudio. Finalmente, se presentan algunas conclusiones.

\section{Aspectos teóricos}

La cooperación internacional ha ocupado una parte fundamental en el desarrollo de las economías caracterizadas dentro del grupo de países menos adelantados o en desarrollo, con el objetivo de que logren ser más competitivas en el ámbito internacional mediante las transacciones comerciales. A través de los años se han propuesto diversos conceptos para describir lo que se debe entender como una economía en desarrollo, uno de ellos es el propuesto por Case \& Fair (2008, p. 460) quienes afirman que "los países del mundo en desarrollo son muy diversos, tanto en sus niveles de vida como en sus experiencias particulares de crecimiento, existen diferencias marcadas que siguen separándolos de las 
naciones desarrolladas. Otras características del desarrollo económico incluyen la necesidad de mejoras en la educación y salud básica".

Las economías en desarrollo deben enfrentar y superar diversas situaciones económicas y sociales a lo largo de su historia, antes de lograr ubicarse como economías desarrolladas, y el camino hacia ese ideal es diferente para cada una de ellas. Por esta razón, los países a lo largo del tiempo han adoptado diversas estrategias en distintas áreas como económica, comercial, social, entre otras, para lograr superar sus obstáculos de desarrollo económico y alcanzar una economía desarrollada que les permita experimentar un equilibrio social, económico y ambiental estable a lo largo del tiempo.

Una de las teorías que enfatizaron al comercio internacional como medio para obtener beneficios económicos es la teoría de ventaja comparativa de David Ricardo, mediante la cual propone una solución estableciendo que aun cuando un país tuviera una desventaja absoluta en la producción de bienes con respecto al otro país, el intercambio es posible y mutuamente beneficioso, puesto que la nación menos eficiente debería especializarse en la producción y exportación del bien en el cual su desventaja absoluta es inferior (este es el bien en el que el país tiene ventaja comparativa). Por otro lado, el país debería importar el bien en el que su desventaja absoluta es superior, o sea, el bien en el que tiene desventaja comparativa (González, 2011).

Siguiendo la lógica de David Ricardo, las economías centroamericanas podrían unir esfuerzos y crear cadenas de valor que contribuyan con el desarrollo saludable de sus sectores productivos; el trabajo conjunto y el conocimiento de sus respectivas debilidades y fortalezas, para lo cual deben definir una línea de trabajo que permita explotar, de manera más dinámica, aquellos sectores que representan mayor dinamismo y tomar decisiones estratégicas sobre las zonas que presentan debilidades. Quintero \& Sánchez (2006) mencionan la cadena de valor como una herramienta de pensamiento estratégico para mejorar la competitividad de las empresas, mientras que Ruiz (2013, p. 1) afirma que "es una herramienta de análisis que facilitan la comprensión de algo tan dinámico e interactivo como es la estrategia de una empresa".

El impulso a sectores con mayor dinamismo debe enmarcarse en un contexto de economía dual, es decir, debe tomar en cuenta las diferencias de productividad existentes entre las economías "agrícolas o tradicionales" y las "no agrícolas-industriales o modernas". Esto debido a las características que comparten las economías centroamericanas y al reconocimiento de tres tipos de sectores que yacen en dichas diferencias, como lo son: sectores de enclave vinculados al mercado mundial, sectores intermedios orientados al mercado interno y sectores de subsistencia con muy baja productividad (Salvia, 2015). Se entiende como productividad cuando se considera un servicio como una operación que nos lleva a una conceptualización de su producción que denominaremos producción directa u operativa, asociada a conceptos de productividad, tales como la productividad directa o, más concretamente, la eficiencia operativa. En este sentido, la productividad del servicio aumentará cuando una misma transformación pueda ser llevada a cabo con menos factores productivos (Sánchez, 2007).

El contexto antes citado pretende dar un enfoque que logre un modelo de acumulación en términos de capital, progreso técnico, recursos naturales y capital humano para potenciar sectores que sean de enclave, e implementar reformas dentro de los sectores intermedios y de subsistencia que permitan el desarrollo (Salvia, 2015); por ello, las economías de la región requieren de inversión y cooperación para identificar, 
Kendall López - Ingrid Arroyo - Cristel Avendaño - Yoselin Ramírez

Línea Base Situacional de la Ayuda para el Comercio en Guatemala y Honduras

priorizar y fortalecer todos aquellos factores de crecimiento interno necesarios para lograr el impulso de sectores claves.

A lo largo de los años, a través de diversos estudios y teorías se ha demostrado que los países son diferentes en cuanto a procesos de desarrollo, ya que unos son capaces de evolucionar de forma más rápida y sostenida, mientras otros requieren de un proceso más largo y difícil. En el marco de esta coyuntura surge la cooperación internacional o cooperación para el desarrollo, que resulta ser medular en el desarrollo de las economías, ya que brinda las herramientas necesarias para invertir y mejorar sus estructuras productivas y lograr, con ello, catalogarse como economías desarrolladas. De este modo, la cooperación para el desarrollo mediante la "ayuda financiera" o "asistencia oficial para el desarrollo" permite abarcar también los flujos de mercado; enfatizar en los países en desarrollo y en los conceptos acordados internacionalmente sobre los logros que la agenda mundial para el desarrollo debería perseguir (Alonso \& Glennie, 2016).

La cooperación para el desarrollo tiene tres objetivos principales: 1. apoyar y complementar a los países en desarrollo en los esfuerzos dirigidos a facilitar las normas sociales básicas universales a su ciudadanía, como medio para que ejerzan sus derechos humanos fundamentales; 2 . promover la convergencia de los países en desarrollo (en especial de los más pobres) con niveles superiores de renta y bienestar, para corregir las desigualdades internacionales extremas; y 3. apoyar los esfuerzos de los países en desarrollo con miras a participar activamente en la provisión de los bienes públicos internacionales (Ocampo, 2015 citado por Alonso \& Glennie, 2016; Severino \& Ray, 2009).

La OMC como organismo multilateral tiene una participación en la asistencia a los países en desarrollo y PMA, específicamente a través de la iniciativa de la Ayuda para el Comercio, la cual tiene por objetivo "prestar asistencia a los países en desarrollo, y en particular los países menos adelantados, para que puedan comerciar" (OMC, s. f., p.1). La AFT agrupa a diversos actores (entes receptores y donantes) para que reconozcan la necesidad de movilizar recursos que impulsen el desarrollo del comercio entre los países.

De acuerdo con el Equipo de Trabajo sobre la Ayuda para el Comercio de la OMC del año 2006, dicha iniciativa agrupa seis categorías (citado por López, 2017):

1. Políticas y reglamentos comerciales.

2. Fomento del comercio.

3. Infraestructura relacionada con el comercio.

4. Creación de capacidad productiva.

5. Ajuste relacionado con el comercio.

6. Otras necesidades relacionadas con el comercio.

Con el objetivo de vigilar y evaluar que se utilicen de manera adecuada los recursos de la iniciativa y promover la transparencia y confianza entre los receptores y donantes, el Equipo de Trabajo sobre la Ayuda para el Comercio declaró que todos los entes proveedores de la Ayuda y los países receptores tenían la obligación de informar sobre los progresos realizados y los resultados obtenidos (WT/COMTD/AFT/W/8. 2 de septiembre de 2008; p. 1 citado por López, 2017). Por lo anterior, surgen los exámenes de la Ayuda, los cuales son el elemento central de la evaluación y vigilancia de la iniciativa. 
Los Exámenes Globales de Ayuda para el Comercio tienen como objetivo reforzar la vigilancia y evaluación de la Ayuda para el Comercio a fin de ofrecer fuertes incentivos tanto a los donantes como a los receptores para llevar adelante el programa de Ayuda para el Comercio (OMC, s.f.). En el año 2007 se realiza el primer examen global como resultado del mandato de la Conferencia de Hong Kong (2005), realizando de manera bianual siete exámenes hasta la actualidad (2007, 2009, 2011, 2013, 2015, 2017, 2019).

Para efectos de esta investigación, la Ayuda para el Comercio se midió con base en los siguientes componentes:

a) Financiación del desarrollo: mide el aporte económico realizado por donantes para financiar proyectos y ayudas de la iniciativa, y el aporte monetario que se otorga para financiar la Ayuda para el Comercio, según las diversas categorías.

b) Costos del comercio: incluye variables que determinan la eficiencia de la economía en lo referente al proceso de exportación, los costos comerciales totales en los que se incurre y el nivel de facilitación al comercio.

c) Indicadores comerciales: pretenden mejorar el desempeño comercial de las empresas y países trabajando de forma directa en las limitaciones de su oferta nacional, con el fin de reducir los costos del comercio o mejorar la capacidad de producción de las empresas.

d) Indicadores de desarrollo: permiten medir o evaluar el impacto a largo plazo que tiene la iniciativa en materia de desarrollo que le permita aumentar su participación en el comercio internacional.

\section{Metodología}

La línea base situacional se determina a partir de los indicadores de la Ayuda para el Comercio que surgen de los Exámenes Globales de Ayuda para el Comercio. La espina dorsal de la investigación se fundamenta en la operacionalización de variables de Ayuda para el Comercio. Así, a partir del marco teórico se extraen los conceptos y proposiciones de: (i) financiación del desarrollo; (ii) costos del comercio; (iii) indicadores comerciales; y (iv) indicadores de desarrollo. Estos conceptos son traducidos en términos operacionales para la elaboración de la línea base.

En esta investigación, cuyo enfoque es mixto predominantemente cuantitativo, se procesan y analizan los datos estadísticos obtenidos de los Exámenes Globales de AFT realizados por la OMC para Guatemala y Honduras. Estos datos son complementados con interpretaciones cualitativas de fuentes tanto primarias como secundarias, de manera que se pueda explicar el comportamiento de dichas variables durante el periodo 2007 al 2019. En la Tabla 1 se muestran las variables mencionadas con sus respectivos indicadores y conceptualización según se establece en los exámenes de la Ayuda para el Comercio. 
Kendall López - Ingrid Arroyo - Cristel Avendaño - Yoselin Ramírez

Línea Base Situacional de la Ayuda para el Comercio en Guatemala y Honduras

\section{Tabla 1. Variables e indicadores a analizar descriptivamente en el marco de la iniciativa de la Ayuda para el Comercio}

\begin{tabular}{l} 
Variables \\
\hline Financiación del desarrollo \\
La financiación del desarrollo se utiliza para financiar las inversiones de capital \\
y el consumo privado y público, y constituye la base del crecimiento y el \\
desarrollo económicos.
\end{tabular}

desarrollo económicos.

\section{Indicadores}

\section{Desembolsos por principales donantes}

Corresponden al aporte monetario para financiar programas y proyectos de Ayuda para el Comercio que realizan el grupo de proveedores de dicha iniciativa.

\section{Desembolsos por sector}

Corresponden al aporte monetario para financiar la iniciativa, según su distribución por categorías.

\section{Costos del comercio}

La sección de costos del comercio incluye indicadores que permiten evaluar de qué forma los costos del comercio relacionados con políticas y la infraestructura de un país han evolucionado en el tiempo, y cuán altos son los costos del comercio en comparación con un grupo de países de referencia.

\section{Conectividad a internet}

Se mide mediante 3 factores. Los abonos a banda ancha móvil o fija se refieren al porcentaje de habitantes abonados a banda ancha móvil o fija en el país. Los particulares usuarios de Internet representan el porcentaje de la población que utiliza Internet.

\section{Costos y tiempo para exportar/importar}

Miden el costo en dólares EE. UU. y el tiempo en número de días que se necesitan para exportar un contenedor de 20 pies lleno desde el depósito hasta el punto de partida del barco transportador de contenedores; o viceversa en el caso de las importaciones.

\section{Índice de desempeño logístico}

El "índice general de desempeño logístico" es un indicador compuesto basado en la apreciación de la logística de un país.

\section{Indicadores de competitividad mundial}

Miden las percepciones que los ejecutivos de empresas tienen del país en relación con el acceso a préstamos y la calidad del suministro eléctrico, de las carreteras, de la infraestructura portuaria y de la infraestructura de transporte aéreo. 


\section{Costos del comercio}

Reflejan, respecto de cada país, los costos comerciales totales, intrarregionales y extrarregionales ad valorem expresados en porcentajes.

\section{Indicadores de facilitación del comercio}

Son indicadores compuestos que miden diferentes aspectos de la facilitación del comercio. La mayoría de ellos están íntimamente relacionados con el Acuerdo sobre Facilitación del Comercio de la OMC

\section{Indicadores Comerciales}

\section{Exportaciones/emportaciones de servicios comerciales}

Hacen referencia a la proporción de los servicios comerciales del país en las

En la sección de indicadores comerciales figuran indicadores que permiten evaluar el desempeño comercial de los países en relación con el valor, el crecimiento, la estructura y la diversificación.

\section{Indicadores de Desarrollo}

La Asistencia Oficial para el Desarrollo (AOD), se toma como un flujo, es decir, esta se

En esta sección se describen las tendencias relativas a los indicadores de desarrollo humano y económico

refiere al apoyo financiero, ya sea de donaciones o préstamos de países miembros del Comité de Ayuda para el Desarrollo (CAD) de la OCDE a países en desarrollo.

\section{Estructura económica}

La misma se realiza con base en una comparación entre dos años dados y mediante la proporción que tienen la agricultura, la industria y los servicios en el PIB del país.

Fuente: Elaboración propia a partir de datos de la Organización Mundial de Comercio (OMC). 2019 
Asimismo, por tratarse de dos países de la región de Centroamérica se utiliza la técnica de estudio de caso en la investigación, la cual, acorde con Eisenhardt (1989), puede considerarse una estrategia de investigación dirigida a comprender las dinámicas presentes en contextos singulares, así puede tratarse del estudio de un único caso o de varios casos, combinando distintos métodos para la recogida de evidencia cualitativa o cuantitativa con el fin de describir, verificar o generar teoría (Martínez, 2006). De acuerdo con Martínez (2006, p. 175):

"[Esta técnica] es adecuada para investigar fenómenos en los que se busca dar respuesta a cómo y por qué ocurren, permite estudiar un tema determinado, permite explorar en forma más profunda y obtener un conocimiento más amplio sobre cada fenómeno, lo cual permite la aparición de nuevas señales sobre los temas que emergen".

Finalmente, para la selección de los casos de estudio (países), el proceso de discriminación utilizado fue el siguiente: la OMC cuenta con 164 miembros desde el 29 de julio de 2016 (OMC, s.f.), de estos la mayoría son países en desarrollo y, particularmente, 36 miembros están catalogados como PMA). Dentro del grupo de países en desarrollo se encuentran las economías de Centroamérica; al ser catalogados de esta manera estos países están sujetos a la iniciativa de la OMC de Ayuda para el Comercio. De este modo, los países debían cumplir con dos criterios básicos e indispensables: (1) ser los más vulnerables de la región y (2) estar incluidos en todos los Exámenes Globales de la AFT realizados por la OMC. Por lo tanto, para definir el criterio (1), se recopilaron y analizaron los datos acerca de los perfiles político, económico, comercial, así como social y demográfico de los países de la región de Centroamérica. En base a estos antecedentes, resultaron ser Guatemala y Honduras los casos de estudio para esta investigación, al cumplir con el criterio de ser parte de los países en desarrollo más vulnerables de la región y estar incluidos en todos los Exámenes Globales de la AFT. Asimismo, es importante aclarar que Costa Rica y Panamá no se seleccionaron como casos de estudio, ya que estos dos países son los que presentan las condiciones económicas más altas de la región, por lo que no encajan en el criterio de país vulnerable.

\section{Línea base situacional de la Ayuda para el Comercio en Guatemala y Honduras}

\section{Contextualización del Financiamiento del Desarrollo en Guatemala y Honduras}

\section{$\underline{\text { Desembolsos por principales donantes }}$}

La Ayuda para el Comercio cuenta con una serie de donantes tanto bilaterales como multilaterales, referidos, respectivamente, a los países e instituciones que contribuyen con la iniciativa mediante la donación de recursos económicos, principalmente. En un inicio este indicador pretende sólo dar un panorama general sobre los contribuyentes, haciendo hincapié en las áreas prioritarias para cada donante de manera que solo se mostraba el grupo de países que contribuía a las áreas de política comercial, infraestructura y capacidad productiva para la clasificación de países según su ingreso (países menos desarrollados, otros países de bajos ingresos, países y territorios de ingresos medios bajos, y países y territorios de ingresos medios altos) (OMC, s.f.). Sin embargo, en la actualidad, la iniciativa destaca cómo los donantes no solo dan un seguimiento a los programas y proyectos con los cuales colaboran, sino que también formulan una estrategia interna al respecto.

Estados Unidos ha desarrollado un marco estratégico para la asistencia exterior, dentro del mismo cuenta con la Agencia para el Desarrollo Internacional de los Estados Unidos (USAID) destinada a ayudar a países en desarrollo para lograr un crecimiento sostenido y competitividad comercial. Por 
esto, para el caso de EEUU los fondos destinados a la AFT se canalizan por esta agencia. Del mismo modo, Japón cuenta con una iniciativa llamada Desarrollo del Comercio, para países de bajos ingresos, donde fomenta el comercio mediante ciertas etapas, y brinda asistencia técnica y financiera en cada una de ellas. Por su parte, la Unión Europea trabaja con una serie de programas enfocados en integración regional para países en desarrollo, y el Banco Mundial realiza estrategias para aumentar su participación en la AFT (OMC, 2009). Estos actores son los donantes que, para los países en estudio, son los más constantes a través de los años y de los cuales dan mayor apoyo económico.

Desde el año 2006 la iniciativa muestra el aporte de cada donante según país receptor; la cual guarda relación con su estrategia interna, prácticas y panorama económico. En lo que respecta a los casos de estudio, para el período comprendido entre los años 2002 y 2005 se clasifica a Guatemala y Honduras como países de ingresos medios bajos, según la categoría se muestra el apoyo de los donantes. Cabe destacar que para dicha categoría de ingreso se da un mayor apoyo en el área de infraestructura económica, la cual comprende todo lo referente al transporte, las comunicaciones y la generación de energía. Los principales donantes para estos países durante este periodo fueron Japón y Estados Unidos, lo cual guarda relación con lo indicado por la OMC (2009), cuando señala que los donantes bilaterales se centran en áreas específicas de los países de ingresos medios, mientras que los donantes multilaterales centran esfuerzos en los países de ingresos bajos.

En el caso de Guatemala, la Figura 1 muestra los donantes con mayor participación del período, según el aporte económico dado. Tomando en cuenta que se recibe un mayor apoyo de donantes bilaterales, Japón resulta el principal donante para Guatemala, con 16.401 millones de USD y figura como donador en la mayoría de los años del estudio; con excepción en el año 2017, donde se mantiene como uno de los principales.

Figura 1. Principales donantes de la AFT para Guatemala durante el periodo 2006-2017. Millones de USD.

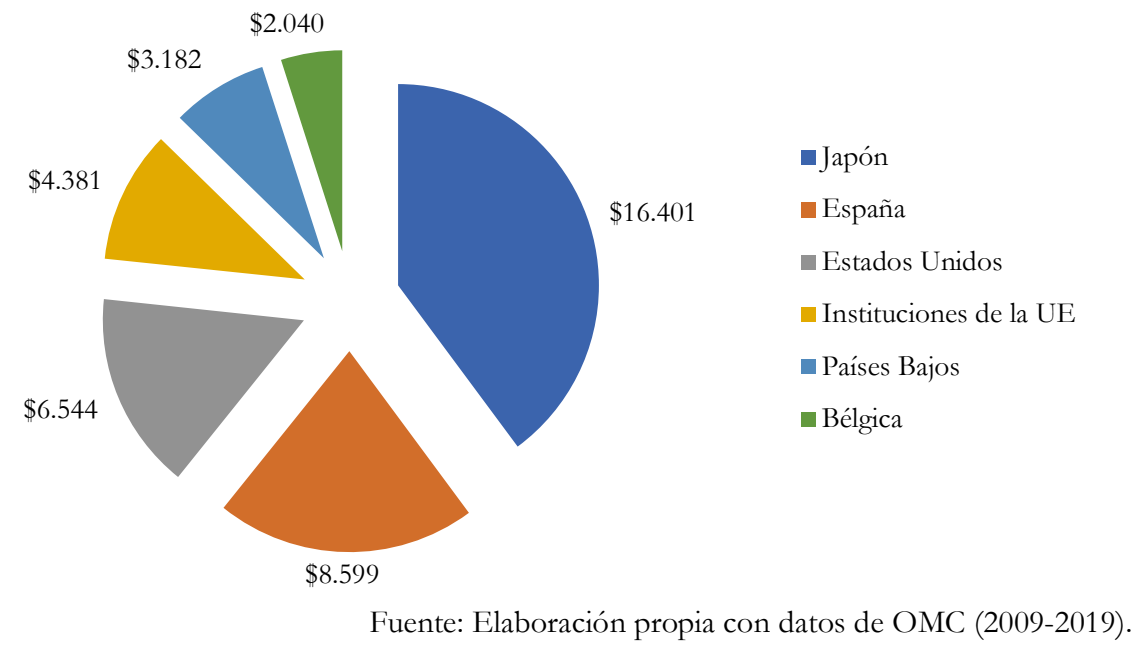

En el caso de Honduras, cuenta tanto con donantes bilaterales como multilaterales. El de mayor aporte es Estados Unidos con 58.559 millones de USD, cifra que resulta casi el 49,3 \% de toda la ayuda recibida por el país durante el periodo comprendido entre 2006- 2017, es decir, del total de desembolsos recibidos por Honduras, casi la mitad corresponden a este donante, como bien lo muestra la Figura 2. 
Kendall López - Ingrid Arroyo - Cristel Avendaño - Yoselin Ramírez

Línea Base Situacional de la Ayuda para el Comercio en Guatemala y Honduras

Figura 2. Principales donantes de AFT para Honduras durante el periodo 2006-2017. Millones de USD.
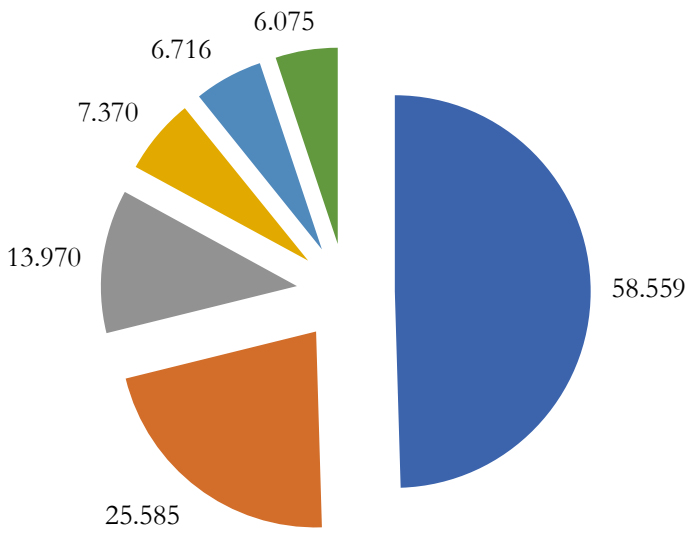

- Estados Unidos

- Banco Mundial

- Japón

Instituciones de la UE

BID

Alemania

Fuente: Elaboración propia con datos de OMC, 2009-2019.

\section{$\underline{\text { Desembolsos por Sector }}$}

Los desembolsos por sector se enfocan en áreas prioritarias como política comercial, infraestructura y capacidad productiva, de acuerdo con las clasificaciones que realiza la OMC de los países con base en sus ingresos. Para el período comprendido entre los años 2002 y 2005, Guatemala y Honduras se clasifican como países de ingresos medios bajos, por esta razón, el mayor aporte estaba dirigido a infraestructura económica, en la cual, de ésta el mayor porcentaje de Ayuda se brindó al sector de transporte y almacenamiento.

En el caso de Guatemala, para el período comprendido entre los años 2006 y 2009, presenta un cambio y como área prioritaria destaca la capacidad productiva, en la cual se destina la mayor cantidad de desembolsos al sector de agricultura, silvicultura y pesca. Para el año 2012 se evidencian una serie de disparidades en el interior del país respecto a la infraestructura de transporte, lo cual indica una baja disponibilidad de caminos, menor acceso a potenciales mercados, entre otros factores limitantes (BID, 2019). En relación con ello, en el año 2013 la mayor parte de desembolsos se destina al sector de transporte y almacenaje.

Para años posteriores el principal sector destino de la Ayuda en Guatemala vuelve a ser la agricultura, silvicultura y pesca, que llega a representar para el año 2017 un total de 37,30 millones de USD (OMC, s.f.). Es así como para la distribución de AFT a lo largo del período entre el año 2006 y el año 2017, los dos sectores destacables son el de agricultura, silvicultura y pesca, y el de transporte y almacenaje, los cuales suman, en el período, un total de aproximadamente 8.575 millones USD y 559 millones de USD, respectivamente (OMC, s.f.).

Por su parte, en Honduras ocurre una dinámica similar, ya que para el período comprendido entre los años 2006 y 2009 presenta como área prioritaria la capacidad productiva y dentro de esta destacan mayores desembolsos para el sector de agricultura, silvicultura y pesca. Sin embargo, para los siguientes años, la dinámica cambia y el sector primario queda rezagado, es decir, los sectores que captan la Ayuda son principalmente el sector de transporte y almacenaje, así como el de generación y suministro de energía. 
Este país centroamericano ha implementado, en los últimos años, un plan de infraestructura que abarca aeropuertos, carreteras y terminales portuarias con el fin de consolidarse como un eje logístico en Centroamérica. De esta forma no solo se pretende mejorar la conectividad dentro del país, sino también con el resto de la región para apoyar áreas como comercio, producción, turismo y logística (Flores, 2017). En relación con ello, el sector de transporte y almacenaje creció para el año 2017 un $6,9 \%$, y un 6,3\% para el año 2018, por el comportamiento positivo de los servicios de transporte terrestres y por el mayor movimiento de carga de bienes destinados al mercado externo (Rodríguez, 2018).

El contexto antes presentado explica cómo la Ayuda recibida por Honduras para el año 2017 se enfoca, principalmente, en el sector de transporte y almacenaje, con un total de 81,73 millones de USD (OMC, s.f.). Cabe recalcar que en la distribución de la AFT del país a lo largo del período comprendido entre el año 2006 y 2017, destacan los sectores de transporte y almacenaje, agricultura, silvicultura y pesca, y generación y suministro de energía; estos suman en el período un total de aproximadamente 43.031 USD, 25.479 USD y 17.469 USD, respectivamente (OMC, s.f.), lo cual resulta coherente con el crecimiento antes mencionado.

\section{Contextualización de los costos del comercio en Guatemala y Honduras}

\section{$\underline{\text { Conectividad a internet }}$}

Dada la adopción tecnológica presentada a nivel mundial como medio para mejorar el desarrollo comercial y económico, el indicador de conectividad a internet aparece por primera vez en el Examen de Ayuda para el Comercio del año 2015. En el caso de Centroamérica, en 2018 se contaba con 22 millones de público usuario con acceso a la web y para ese año Guatemala era el país con mayor cantidad de sujetos usuarios de internet con aproximadamente siete millones de personas conectadas a la red; es decir, de 10, tres o cuatro están conectadas (Barrera, 2018).

Para el 2018, la principal fuente de conectividad eran los dispositivos móviles, ya que, de los 22 millones de sujetos conectados, 18 millones lo hacían por medio de su celular, lo cual apuntaba a un nuevo estilo de vida digital. Según la Figura 3, respecto a Guatemala y Honduras, se puede señalar el avance que se ha tenido en este rubro entre los años 2013 y 2017, donde ambos países han manifestado un aumento sostenido más no significativo, es decir, se cuenta con mayor acceso, pero aún se presentan dificultades en su desarrollo.

En el caso de Guatemala, la población conectada pasó de un 19,7\% para el año 2013 a un 40,7\% para el año 2017, más para ese último año los abonos de banda ancha fija y móvil, pese a presentar aumentos, no superan entre ambos el 20\%, según datos presentados en los exámenes (Figura 3). La penetración de Internet concentra un alto porcentaje en la ciudad capital y sus municipios periféricos, por lo cual, si bien la adopción de esta va a pasos acelerados, la cobertura aún es baja (Melgar, 2016). 
Kendall López - Ingrid Arroyo - Cristel Avendaño - Yoselin Ramírez

Línea Base Situacional de la Ayuda para el Comercio en Guatemala y Honduras

Figura 3. Conectividad a internet en Guatemala y Honduras en los años 2013, 2015 y 2017 (\% de la población)

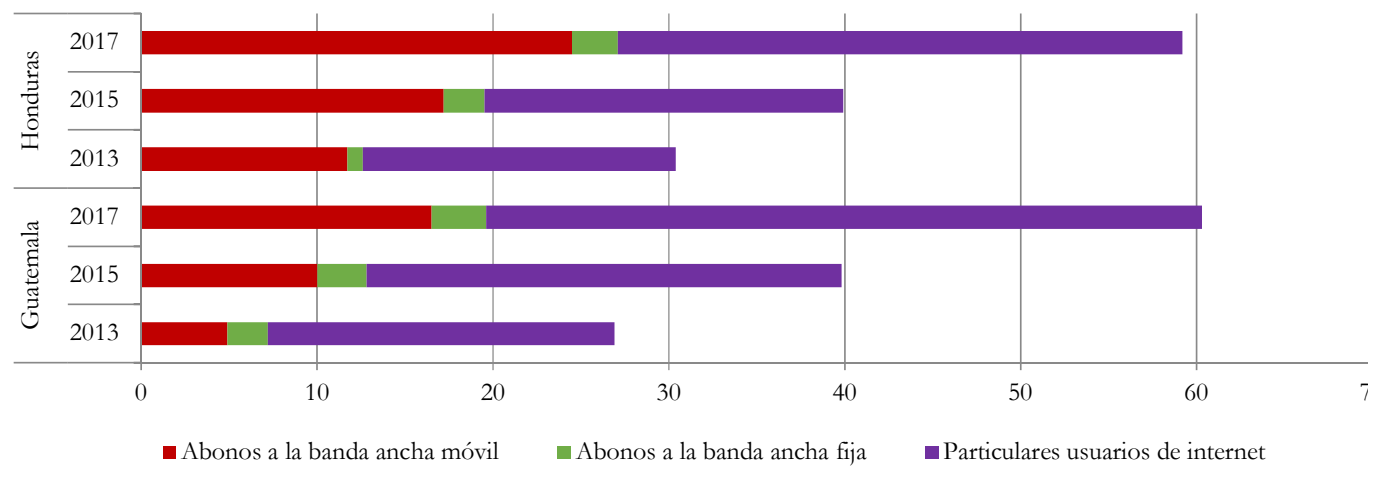

Fuente: Elaboración propia con datos de la OMC (s.f.)

A pesar de que la economía digital está creciendo y los países de Centroamérica están avanzados en este tema, no es suficiente para competir a nivel internacional. Los países centroamericanos deben aunar esfuerzos para disminuir, de manera drástica, la brecha digital, por lo que deben enfocar sus esfuerzos y recursos en mejorar la infraestructura de comunicaciones, acceso a la educación y aumentar la capacidad de producir riqueza (Melgar, 2017). Por ende, aunque las economías centroamericanas han mejorado en temas de conectividad, continúan por debajo de los niveles internacionales.

\section{Costos para exportar e importar}

Los costos y tiempos para exportar e importar son analizados por el Doing Business del Banco Mundial. Su función es medir el tiempo de duración del proceso de exportación e importación y los costos asociados en el intercambio de bienes (Banco Mundial, 2015). Los procedimientos que se miden en el Doing Business y que analiza la OMC en el Examen Global de la Ayuda para el Comercio son el cumplimiento documental y el cumplimiento transfronterizo dentro los procesos de intercambio comercial, tanto en tiempo como en costos. El cumplimiento documental consiste en el tiempo y costo asociados con los requisitos documentales de todas las agencias gubernamentales de la economía de origen, de destino y cualquier economía de tránsito. Para esto, mide el tiempo dedicado a:

1. Obtener el documento emitido y sellado,

2. recopilar la información para completar los documentos comerciales,

3. esperar que la autoridad pertinente emita el permiso,

4. mostrar el recibo de terminal portuaria a las autoridades,

5. la presentación de los documentos a la agencia de aduanas.

Mientras tanto, en el cumplimiento fronterizo se examina el tiempo y los costos relacionados con el cumplimiento de las regulaciones aduaneras de la economía y con las regulaciones de otras inspecciones obligatorias (como las fitosanitarias) para que el envío pueda cruzar frontera inclusive si no se realizan en aduanas (Banco Mundial, 2015). Cabe recalcar que los dos primeros años contemplados en los exámenes globales son el 2011 y el 2014; en estos, los días se presentan en forma general sin detallar el tiempo de duración invertido en cada uno de los procedimientos. 
En Guatemala, los procedimientos de exportación, importación y de tránsito han presentado mejoras gracias a la implementación del sistema de ventanilla única de comercio exterior (VUCE) que busca simplificar y agilizar la gestión de trámites de exportación, importación y actividades derivadas al comercio internacional, de forma electrónica y desde un único punto de entrada. Este sistema coordina las instituciones involucradas en trámites y procedimientos de comercialización externa de los productos guatemaltecos (AGEXPORT, s.f.). En 2000, se implementó el sistema aduanero automatizado (SIDUNEA) desarrollado por la UNCTAD, y en el año 2001, puso en funcionamiento el sistema informático Sistema Integral Aduanero de Guatemala (SIAG) (INFOCENTREX, 2007).

En 2013, en conjunto con 11 distintas instituciones públicas crearon la Ventanilla Ágil de Importaciones (VAI) para facilitar los trámites de importación. Adicionalmente, cuentan con un sistema electrónico de autorización de exportaciones (SEADEX), un documento de declaración para registro y control de exportaciones (DEPREX) y una Oficina de Regímenes de Perfeccionamiento Activo (OPA) (AGEXPORT, s.f.). Este país es uno de los pocos que a nivel de Centroamérica se ha esforzado por la automatización de los procedimientos, y todas estas acciones permiten la reducción de los costos y los tiempos, requeridos por estos trámites, y facilitan la gestión del gobierno para verificar el cumplimiento de los requisitos (INFOCENTREX, 2007).

En ese sentido, la Figura 4 muestra una disminución en el tiempo de realización de los procedimientos para exportar e importar. En el año 2011, el tiempo promedio era de 17 días mientras que en 2018 (año más actual) fue de seis días, es decir, 11 días menos. En 2016, año en el que se presentó menor tiempo con un promedio de cinco días, se obtuvo en cumplimiento en frontera para exportar de un día y para importar dos días; mientras que en cumplimiento de documentación correspondió al exportar a dos días y cuatro para importar; es decir, el tiempo para importar fue el doble que el de exportar.

Figura 4. Guatemala. Tiempo para exportar e importar en días.

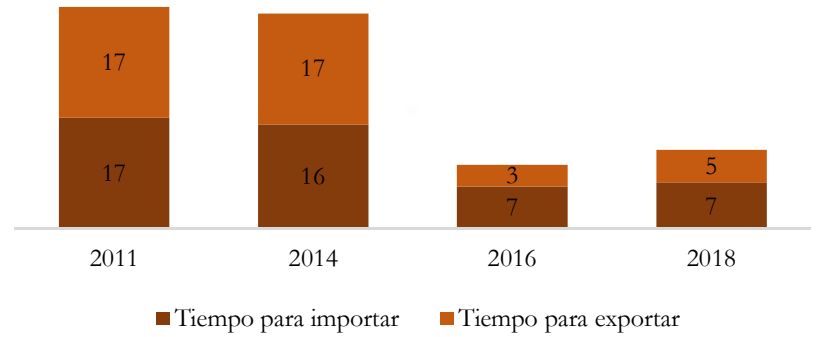

Fuente: Elaboración propia con datos de la OMC (s.f.)

En 2018, el tiempo para exportar fue mayor porque requirió 0,5 días más que en 2016 en cumplimiento de fronteras y 1,2 días más que en el año 2016 en cumplimiento de documentación. Esto deja en evidencia que Guatemala aún continúa en el proceso de agilización de estos trámites y que, a pesar de que en el último año tuvo un leve aumento, ha mejorado significativamente en comparación con los dos primeros años estudiados.

En cuanto a costos para exportar e importar, se visualiza en la Figura 5 que también se han reducido, gracias a las acciones realizadas por el país. En el año 2011, el costo promedio fue de 1,216 USD, aunque en 2014 se elevó a 1,475 USD, es decir, un aumento de 25\%, en los siguientes años se logra apreciar una disminución significativa. 
Kendall López - Ingrid Arroyo - Cristel Avendaño - Yoselin Ramírez

Línea Base Situacional de la Ayuda para el Comercio en Guatemala y Honduras

Figura 5. Guatemala. Costos para exportar e importar (USD)

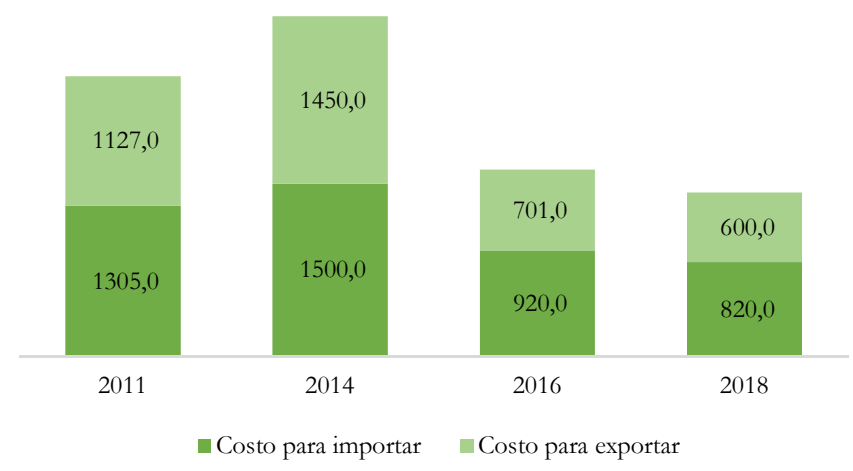

Fuente: Elaboración propia con datos de la OMC (s.f.)

En el año 2016, es donde se refleja la reducción más importante, ya que el costo promedio fue de 811 USD, con una diferencia del $45 \%$ con respecto al 2014. En este período la exportación tenía un costo de 300 USD en cumplimiento de frontera y 401 USD en cumplimiento documentación; y el costo de la importación quedó en 400 USD en cumplimiento de fronteras y 530 USD en cumplimiento de documentación.

Mientras que, en el año 2018, el costo promedio disminuyó a 100 USD, y quedó en una cifra de 710 en total; el costo para exportar fue de 200 USD en cumplimiento de frontera y 400 USD en cumplimiento de documentación. Para el caso de la importación, el costo en cumplimiento en frontera fue de 400 USD y 420 USD en cumplimiento de documentación; lo que evidencia una disminución continua en el costo de los procedimientos aduaneros.

Honduras, por su parte, cuenta con la Dirección de Trámites Empresariales que es la encargada del Centro de Trámites de Exportación (CENTREX), la cual tiene como objetivo centralizar la ejecución de todos los trámites relacionados con las exportaciones del país (Gobierno de Honduras, s.f.). Entre los trámites que atiende CENTREX están (CENTREX, 2017):

1. La Declaración Única Aduanera (DUA), que contiene las tres principales declaraciones aduaneras que ampara el comercio de mercancías en la región; esta se está aplicando actualmente para reducir la cantidad de tramitología.

2. El permiso fitosanitario o zoosanitario.

3. La Declaración de exportación y la constancia sobre minería, si se requiere.

Aunado a lo anterior, la Comisión Presidencial de Reforma Integral del Sistema Aduanero y Operadores de Comercio (COPRISAO), con el objetivo de agilizar los trámites en las aduanas hondureñas, sostuvo reuniones durante el 2017 con el sector privado para conocer sus inquietudes. Además realizó visitas a las aduanas para conocer su operatividad. El resultado principal fue la queja de los entes importadores, exportadores y agentes aduaneros sobre la lentitud en el retiro de las mercancías (Rodríguez, 2017).

En 2011, el tiempo promedio era de 20 días mientras que en el año más actual estudiado (2018) fue de seis días, es decir, 14 días menos. En 2016, el tiempo de la importación correspondió a cuatro días en cumplimiento en fronteras y siete días en cumplimiento de documentación; no obstante, en 2018 
la variación no fue significativa, puesto que mantuvo el mismo tiempo de cuatro días en cumplimiento de fronteras y siete días en el de documentación.

Figura 6. Honduras. Tiempo para exportar e importar en días

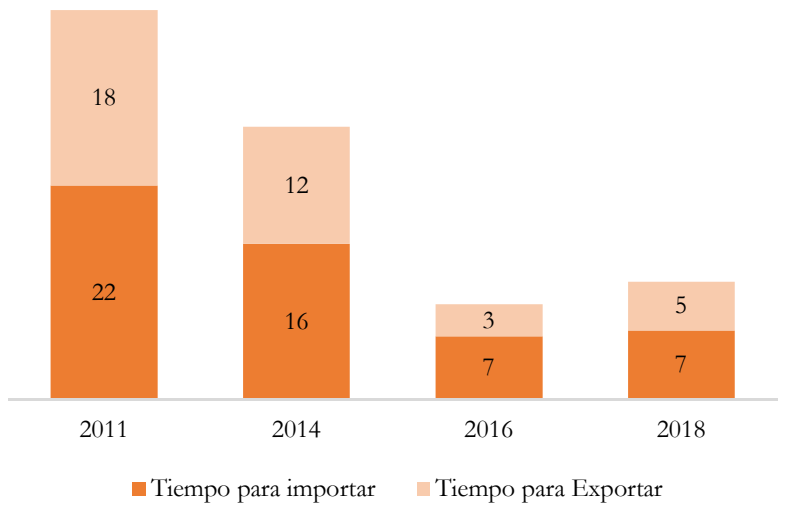

Fuente: Elaboración propia con datos de la OMC (s.f.)

Para los procesos de exportación fue similar, debido a que en el año 2018 el tiempo en cumplimiento de fronteras fue de cuatro días y el de cumplimiento de documentación fue de siete días. Sin embargo, en 2018, el tiempo en cumplimiento de fronteras se mantuvo en cuatro días, pero en cumplimiento de documentación disminuyó a seis días, lo cual es un indicador de que los tiempos están siendo reducidos y puede el país establecer acciones dirigidas a la agilización de los procedimientos aduaneros y, posteriormente, alcanzar mayores oportunidades de desarrollo.

En materia de costos de exportación e importación, Honduras presenta complicaciones, ya que estos son altos y sin tendencia a la baja, encarecidos no solo por los procedimientos aduaneros sino también por las malas condiciones de infraestructura del país y otros factores evaluados por el índice de desempeño logístico. En el año 2011, el costo promedio fue de 1,331 dólares USD, mientras que en 2014 se elevó a 1,450 USD, es decir, aumentó en un 9\%. A pesar de esto, en el año 2016, el costo promedio disminuyó un $28 \%$; los costos tanto para exportar e importar se mantuvieron iguales, y fueron en cumplimiento 490 USD y en cumplimiento de documentación 550 USD.

Figura 7. Honduras. Costos para exportar e importar

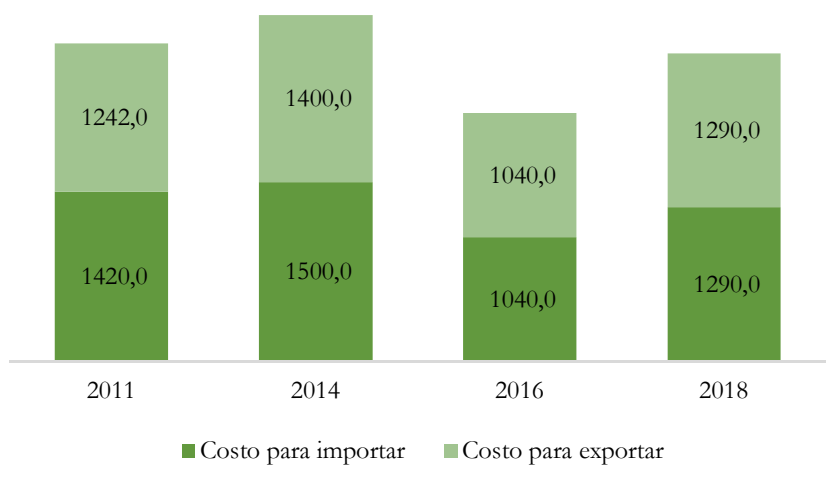

Fuente: Elaboración propia con datos de la OMC (s.f.) 
En cuanto al año 2018, el costo promedio aumentó un 24\%, los costos tanto para importar como para exportar se mantuvieron en 600 USD en cumplimiento de frontera y 690 USD en cumplimiento de documentación. Si estos se comparan con el 2016, en cumplimiento en fronteras el costo aumentó en $22 \%$ y el de cumplimiento de documentación en un $25 \%$.

\section{Índice de desempeño logístico}

La OMC considera al índice de desempeño logístico (o LPI, por sus siglas en inglés) ${ }^{1}$ como indicador global que evalúa aspectos de aduanas, infraestructura, envíos internacionales, competencia de servicios logísticos, seguimiento y rastreo, y puntualidad. En ese sentido, fue incorporado a partir del año 2013 en los exámenes globales del AFT. Los resultados de los exámenes AFT muestran los resultados del índice de desempeño logístico que presenta Guatemala, con una puntuación de 2,6, considerado el promedio de los años que se muestran en la Figura 8, con respecto a los seis aspectos evaluados por el índice.

\section{Figura 8. Índice de desempeño logístico de Guatemala}

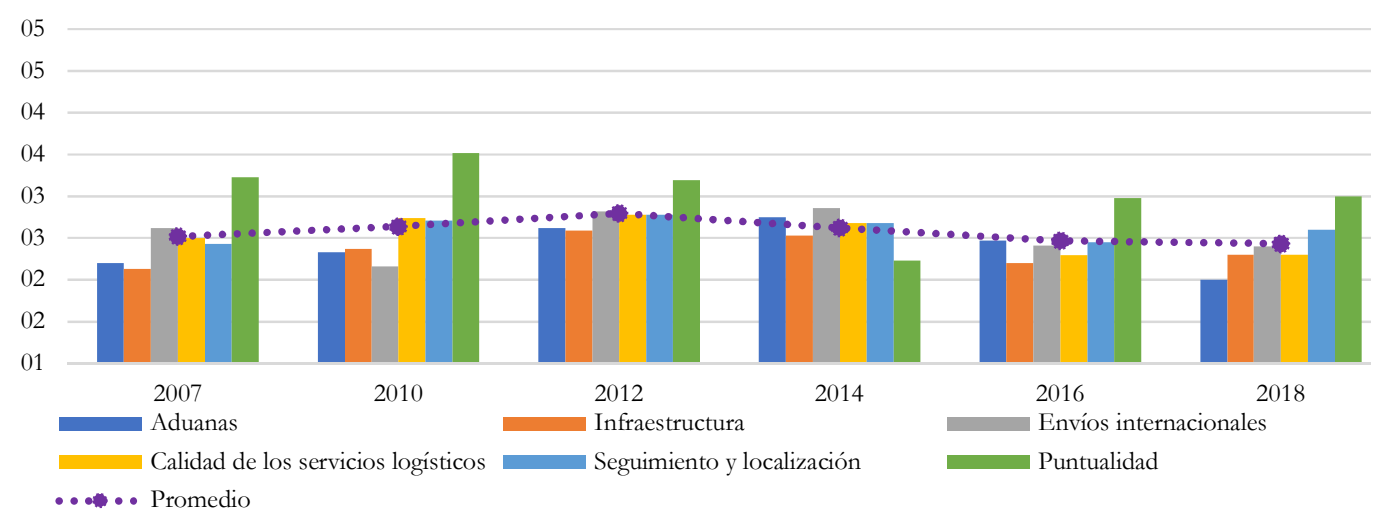

Fuente: Elaboración propia con datos de la OMC (s.f.)

En la evaluación del LPI de Guatemala, se observa que el aspecto que más afecta el desempeño logístico es la infraestructura (la calidad de la infraestructura del comercio y transporte) pues, según la mayoría de los años evaluados, presenta la menor puntuación entre 2,0 y 2,5 (Figura 8). En efecto, de acuerdo con BID (2019, citando a la ICEFI (2012)), la calidad de la infraestructura del transporte muestra disparidades al interior del país. Esto principalmente en las regiones que concentran mayores niveles de pobreza, las que presentan una baja densidad en caminos transitables. Asimismo, este estudio indica que la densidad vial interna en Guatemala es de $1,2 \mathrm{~km} / 1.000$ habitantes, esta es superada al doble por la de países vecinos que corresponde a $3 \mathrm{~km} / 1.000$ habitantes; y si se le suma el escaso desempeño logístico fronterizo, se disminuyen las posibilidades de acceder a nuevos mercados internacionales.

Siguiendo con los resultados de los exámenes AFT mostrados en la Figura 8, el segundo aspecto que se refleja con menor puntuación en el año 2018 es el de aduanas con 2,2. Este resultado obedece, según un estudio realizado por el BID (2019), a un nivel de ineficacia de los procedimientos de

${ }^{1}$ El LPI pretende identificar los desafíos y oportunidades que mejoren el desempeño logístico, al medir seis aspectos en un rango de 1 a 5 , donde 1 es la puntuación más baja y 5 la más alta. Cuanto más alta sea la calificación mayor es el desempeño. El resultado final sería un promedio ponderado de los puntajes obtenidos por todos los aspectos evaluados (Consejo Nacional de Competitividad, 2018). 
despacho aduanero y en frontera. Este, en conjunto con la baja calidad de infraestructura, se convierten en la principal razón de rezago, ya que la ineficiencia incrementa los costos y reduce la predictibilidad del movimiento de cargas internacionales por vías terrestres.

En Honduras, según la evaluación de LPI de la figura 9, el aspecto que más afecta el desempeño logístico es la infraestructura (la calidad de la infraestructura del comercio y transporte), debido a que en la mayoría de los años recibe las puntuaciones más bajas. De acuerdo con el BID (2019), en el país son evidentes las deficiencias en transporte y logística que comprometen su competitividad, y en el índice de desempeño logístico del año 2018, fue el que presentó los peores resultados con respecto a los países de América Latina y el Caribe, por sus deficiencias en infraestructura y falta de calidad en los servicios. En el nivel centroamericano, es el que presenta la densidad vial más baja $\left(0,30 \mathrm{~km} / \mathrm{kms}^{2}\right)$ y solo están pavimentados $24 \%$ de los $15.000 \mathrm{~km}$ de la red vial, lo cual afecta al comercio tanto nacional como internacional, al ser el transporte terrestre el medio más utilizado de esta red. Además, el estudio recalca que con US $\$ 0,07 / \mathrm{km}$, Honduras tiene uno de los costos de transporte vial más altos de la región. A pesar de la importancia de la infraestructura vial, la inversión pública ha sido limitada, al igual que los recursos destinados a dar mantenimiento a los caminos.

\section{Figura 9. Índice de desempeño logístico de Honduras}

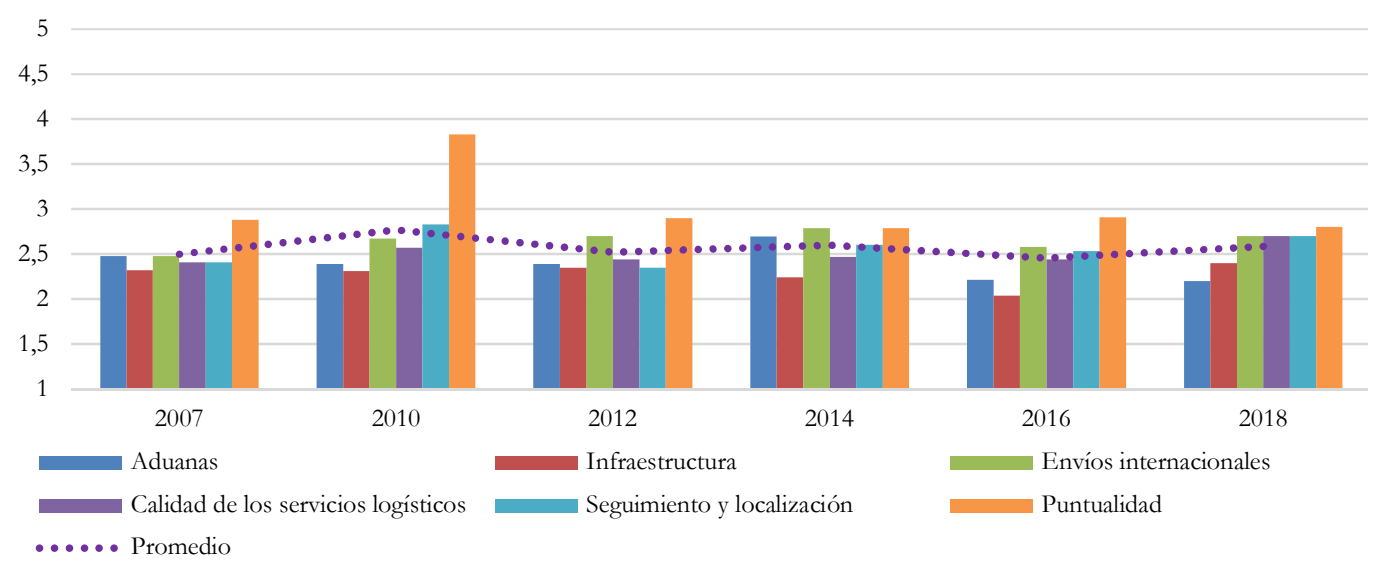

Fuente: Elaboración propia con datos de la OMC (s.f.)

Por otro lado, la inversión pública en infraestructura representa en promedio 1,2\% del PIB, el tercero más bajo de América Latina, comparado con el promedio regional de 2,6\% del PIB. La cobertura territorial no es equilibrada, y hay desigualdades considerables según los departamentos, además la conectividad en las zonas rurales es limitada. Este desequilibrio refleja las debilidades institucionales del sector, entre las cuales se encuentran los problemas relacionados con la planificación, la priorización, la ejecución, el mantenimiento de las inversiones y la asignación de recursos (BID, 2019).

Entonces, tomando los resultados de los exámenes AFT y el informe del BID, se evidencian los retos que debe enfrentar el país para lograr un óptimo desempeño logístico y mejorar su posición competitiva de manera que le permita un mejor desarrollo.

\section{Indicadores de competitividad mundial}

Los indicadores de competitividad mundial miden las percepciones originadas por los ejecutivos de empresas, en relación con los factores que intervienen en el desarrollo económico de un país. Estos 
Kendall López - Ingrid Arroyo - Cristel Avendaño - Yoselin Ramírez

Línea Base Situacional de la Ayuda para el Comercio en Guatemala y Honduras

están dados por el acceso a préstamos, y la calidad de suministro eléctrico, de las carreteras y de la infraestructura tanto portuaria como de transporte aéreo. Están expresados en una escala de 1 a 7 , donde 1 es el nivel más bajo y 7 el óptimo (OMC, 2015).

En Guatemala, los pilares evaluados en los tres años seleccionados se mantienen en una puntuación variada según se observa en la Figura 10, la puntuación promedio es de 3,8. Los pilares con puntuación más alta son el acceso a préstamos (4,0 en promedio) e infraestructura del transporte aéreo (4,0 en promedio), los cuales aún no alcanzan a ser óptimos, pero pueden hacerlo en corto plazo, si se ejecutan acciones para mejorar.

Posteriormente, el tercer pilar con mejor puntuación promedio es el de suministro eléctrico con 5,5 en promedio de los años 2014 y 2016 (Figura 10). Este sector está regulado por el Ministerio de Energía y Minas (MEM), que vela por suministrar energía eléctrica en condiciones óptimas de seguridad, calidad y precio; y cuenta con políticas regulatorias como la política energética que define los objetivos para fortalecer este subsector (MEM, 2017). Por otro lado, dicho gráfico muestra que el pilar con menor puntuación es carreteras (puntuación promedio 3,3), pues su calidad es muy baja y afecta el desarrollo del país.

De acuerdo con FUNDESA (2016), la infraestructura vial está compuesta por $16.547 \mathrm{~km}$ de longitud; y se divide en cuatro categorías; la red primaria es la que probablemente despierta mayor interés en el público, pero esta representa solamente el 22,5\% del total de kilómetros. Es la red terciaria, en su mayoría de terracería, la que representa la mayor porción de la red vial $(40,2 \%)$, seguida de la red de caminos rurales (26,3\%); esto representa un retraso a nivel internacional, el 39,7\% de la red vial pavimentada requiere mantenimiento mayor; adicional, el mismo estudio indica que casi el $60 \%$ del total de la red vial está en condiciones deficientes, en un proceso de deterioro acelerado.

\section{Figura 10. Guatemala. Indicadores de competitividad}

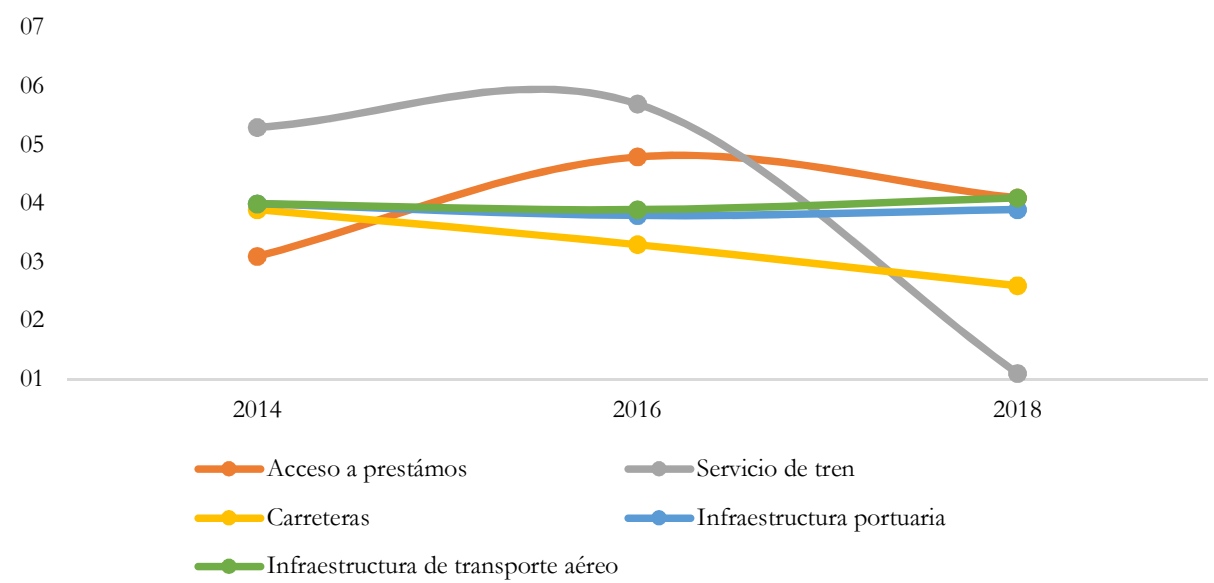

Fuente: Elaboración propia con datos de la OMC (s. f.).

La desatención de la red vial repercute en la velocidad de traslado en las rutas principales. La velocidad promedio en ruta es de 31 kilómetros por hora (en 2017), lo que equivale a una pérdida de siete kilómetros por hora respecto al 2015, y representa un 16\% de pérdida en solo dos años. En consecuencia, la pérdida de velocidad se traduce en mayores costos a toda la población, que serán reflejados en el precio de los productos y otras actividades productivas (FUNDESA, 2016). 
En síntesis, en Guatemala la red vial está compuesta por 16.467 kilómetros, y esta se divide en la red primaria que representa el $22,5 \%$ del total de kilómetros, la red terciaria que representa la mayor proporción del $40,2 \%$ y que en su mayoría es terracería; y, por último, la red de caminos rurales que representa el 26,3\%. Estas cifras a nivel internacional son un grado significativo de retraso, puesto que solo el 44,6\% está pavimentado; y la red vial no pavimentada corresponde a 359 metros por $\mathrm{km}^{2}$ de superficie, de manera que queda por encima de todos los países centroamericanos (FUNDESA, 2016).

El segundo pilar de puntuación más baja es el de infraestructura portuaria. Según un estudio realizado por el BID (2013), en Guatemala el sistema portuario es deficiente, ya que al no contar con grúas en funcionamiento sólo pueden recibir buques que tengan grúa a bordo. En Puerto Barrios y en Puerto Santo Tomás de Castilla pueden recibir los buques alimentadores que requieren una profundidad de 10,7 metros; además puede recibir en Puerto Quetzal los buques Panamax (con profundidad de calado entre 10,7 y 12,5 metros); pero ninguno de los puertos cuenta con equipo necesario para recibir los buques Post-Panamax.

En Honduras, los pilares del indicador de competitividad mundial se mantienen con una puntuación similar en los tres años (Figura 11). En promedio, la puntuación es de 3,7; las puntuaciones más altas son la de infraestructura portuaria (4,3 en promedio) y la de infraestructura de transporte aéreo $(4,1$ en promedio). Ello refleja que el país no tiene las condiciones óptimas para lograr un desarrollo comercial eficiente, aunque podría realizarlo implementando mejores estrategias de desarrollo.

\section{Figura 11. Honduras. Indicadores de competitividad}

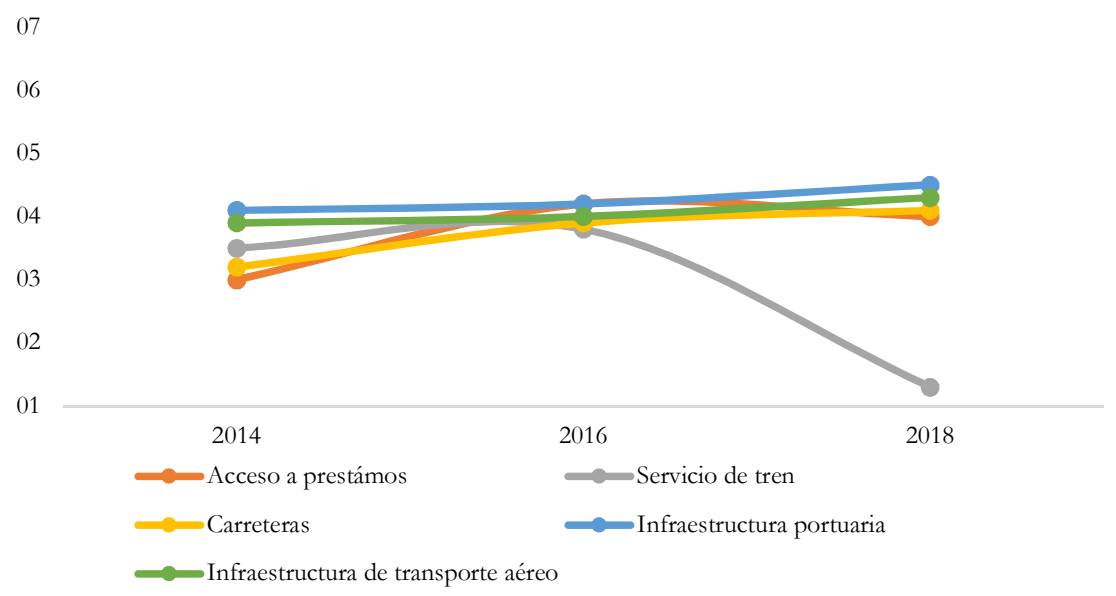

Fuente: Elaboración propia con datos de la OMC (s. f.).

En cuanto a las puntuaciones más bajas, estas recaen en servicio eléctrico, carreteras y acceso a préstamos con 3,7 cada uno. En cuanto a energía eléctrica el país ha evolucionado de la dependencia de la generación mediante petróleo. En efecto, en el año 2012, el 56,9\% del total de electricidad era generada por centrales termoeléctricas convencionales que utilizan combustible, mientras que el restante 43,1\% era generado por plantas de energía renovable (Gobierno de Honduras, 2016).

Posteriormente, las carreteras es el segundo rubro más bajo según se observa en la Figura 11. A pesar de que presenta una mejora en los períodos seleccionados, la puntuación promedio es de 3,7. Tal como lo indica el BID (2016), la infraestructura vial en Honduras es deficiente y es necesaria la inversión en carreteras para alcanzar mayor efectividad en el comercio de bienes y servicios, y, 
Kendall López - Ingrid Arroyo - Cristel Avendaño - Yoselin Ramírez

Línea Base Situacional de la Ayuda para el Comercio en Guatemala y Honduras

consecuentemente, lograr ser un país más competitivo. El tercer pilar con menor puntuación es el acceso a crédito. Las instituciones financieras hondureñas que concentran el mayor tamaño en activos dentro del sistema financiero son los bancos de primer piso $(90,1 \%)$, las cooperativas $(4,1 \%)$ y las aseguradoras $(2,8 \%)$; y estos abarcan $67 \%$ del territorio nacional.

Sin embargo, hay exclusión financiera hacia algunos sectores como el de micro y pequeños grupos agricultores, receptores de remesas, beneficiarios de transferencias monetarias condicionadas, micro y pequeños comercios, y las personas asalariadas que demandan créditos de vivienda y perciben un salario mínimo o menos (Valenzuela \& Cruz, 2017). De esos sectores, lo más afectados son los de las micro y pequeñas producciones agrícolas, debido a que son el segmento tradicionalmente excluido en el país por el riesgo que perciben de habitar en zonas rurales y la mayoría tienen una limitada o inexistente presencia financiera; en efecto, este segmento había tenido acceso a 15 créditos en promedio en instituciones financieras cuyas principales fuentes de financiamiento estaban constituidas por cooperativas y asociaciones (25\%), parientes o amistades $(18 \%)$ y bancos privados (15\%) (Valenzuela \& Cruz, 2017).

\section{$\underline{\text { Indicadores de facilitación de comercio }}$}

La facilitación del comercio consiste en la simplificación y armonización de los procedimientos que rigen el comercio internacional, por lo que involucra los procedimientos de exportación e importación, formalidades del transporte, pagos, seguros y otras exigencias financieras (INFOCENTREX, 2007). Los indicadores de facilitación de comercio fueron elaborados por la Organización de Cooperación y Desarrollo Económico (OCDE) para dar a conocer, a los países, las prioridades de aplicación en el ámbito de facilitación de comercio para destinar asistencia técnica y la creación de capacidad a las esferas que más necesiten (OMC, 2015).

Es importante resaltar que los resultados del análisis de los indicadores de facilitación del comercio tienen una relación positiva entre las mejoras del rendimiento resultante de la facilitación de comercio y la participación en las cadenas de valor mundiales. La iniciativa del AFT aborda diversas áreas políticas que afectan la interacción de los países en las cadenas globales de valor, principalmente la facilitación de comercio y mejora en infraestructura, por lo que en el Acuerdo sobre Facilitación del Comercio (AFC) de la OMC representa una oportunidad histórica de agilizar los procedimientos en frontera y reducir los costos del comercio (OMC, 2015).

La facilitación al comercio evalúa la disponibilidad de que la información comercial esté actualizada, sea suficiente y fácilmente accesible, así como la existencia de requisitos de documentación simplificados y armonizados a nivel internacional, las resoluciones anticipadas que corresponden a respuestas a los exportadores e importadores en el marco del tratado de libre comercio respecto a los asuntos que el tratado en particular regule (MINECO, s.f.), los procedimientos de recurso y procedimientos generales, gobernanza e imparcialidad (OMC, 2015). En Guatemala el indicador de facilitación de comercio mejoró entre el 2015 al 2017 en un 4\%.

De la puntuación máxima de dos puntos, Guatemala obtuvo un promedio de 1,5 entre ambos años, lo que lo constituye en un país que presenta simplificación de procedimientos y trámites. Asimismo, también se muestra en los costos y tiempos al exportar, que se han reducido significativamente por las acciones de sistematización que ha realizado. En la Figura 12 se muestra que la dimensión de disponibilidad de la información es la que tiene la puntuación más alta (en promedio 1,7), posteriormente con una puntuación promedio de 1,6 están las resoluciones anticipadas, evidencia de la calidad de respuesta a los entes participantes del comercio internacional. En cuanto a los pilares 
más bajos, se encuentra la automatización y los procedimientos generales con puntuaciones promedio de 1,1 en ambos casos.

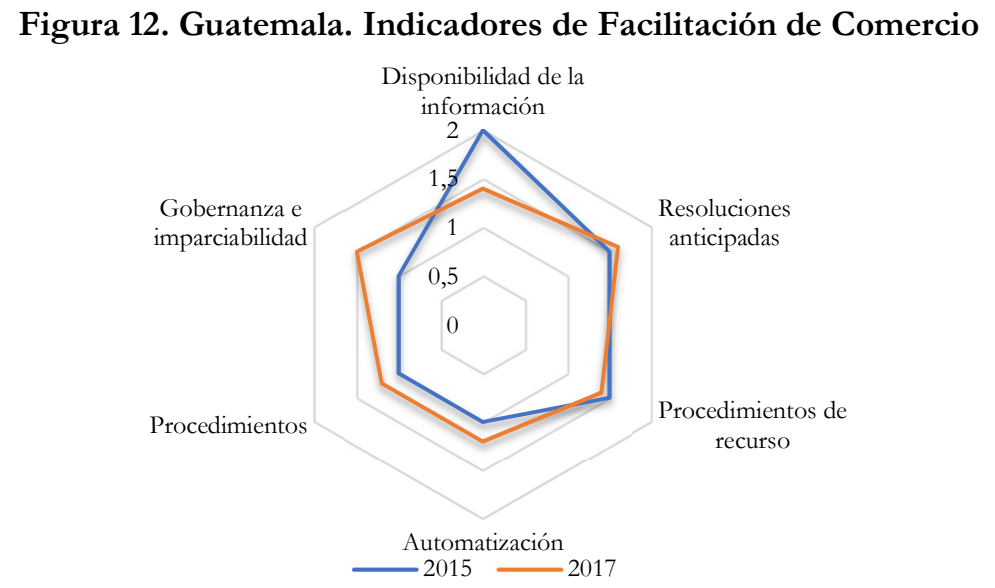

Fuente: Elaboración propia con datos de la OMC (s.f.)

A pesar de que el país ha tenido avances en procedimientos comerciales, en términos generales el indicador muestra que aún es deficiente. En cuanto a la automatización cuenta con acceso limitado a la tecnología. Sin embargo, muchas empresas se actualizan en este aspecto, de forma específica en procesos e implementación de proyectos para automatizar procesos para integrar las diferentes áreas que permitan entregar al usuario final información confiable y en tiempo real (Sazo et al., 2011).

En Honduras por su parte, del año 2015 al 2017, la puntuación promedio disminuyó en -24\%, principalmente por la baja puntualidad en procedimientos, automatización y gobernanza, con puntuaciones promedios de 0,6, 0,9 y 0,9, respectivamente (Figura 13). En la automatización y los procedimientos que han sido implementadas por algunas empresas han logrado reducir el costo de transacción de $8,7 \%$ a 5,7\% del valor de la propiedad y ha reducido el número promedio de días requeridos para registrar una propiedad de 35 días en 2006 a 29 días en 2017 (Banco Mundial, s.f.). No obstante, el indicador muestra que no es suficiente el nivel de automatización, lo cual puede afectar también los procedimientos generales.

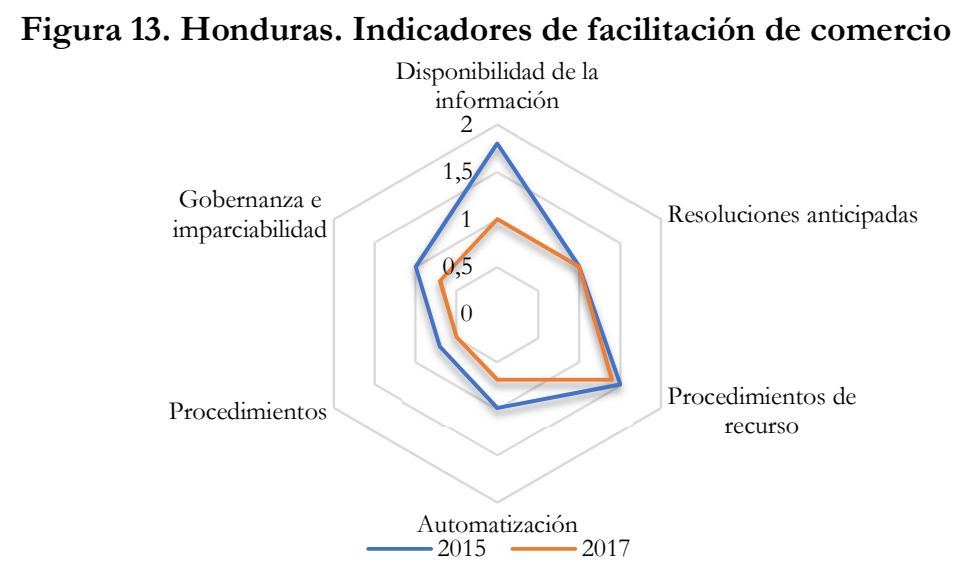

Fuente: Elaboración propia con datos de la OMC (s.f.).

En cuanto a la gobernanza, en el año 2015 obtuvo una puntuación de 1,0, mientras que en 2017 bajó a 0,7 , lo que muestra un empeoramiento en la intervención del Estado en las actividades económicas 
y, por ende, el desarrollo del país no tendrá resultados eficientes. Por otro lado, los pilares con mayor puntuación son los procedimientos de recursos y la disponibilidad de información con 1,5 y 1,4 en promedio, lo que evidencia que el país tiene pilares fuertes que puede aprovechar y tomar como base para impulsar su desarrollo.

En general, tanto Guatemala como Honduras son países que tienen recursos limitados y una estructura poco eficiente que no les dificulta el acceso a mejores tecnologías. A pesar de esto, han logrado avances en áreas como la reducción en tiempos y costos comerciales que, sin duda, contribuyen a transacciones comerciales más productivas $\mathrm{y}$, adicionalmente, fomentan un mejor servicio de cara al público tanto nacional como internacional. Sin embargo, aún es necesario romper con las barreras estructurales que imposibilitan la implementación de acciones de trabajo que contribuyan con la eficiencia y productividad, así como también priorizar la adopción de nuevas tecnologías y adaptar al país a estas herramientas, como herramientas claves que les permitan salir del rezago económico.

\section{Contextualización de los indicadores comerciales en Guatemala y Honduras}

\section{Exportaciones/importaciones de servicios comerciales}

Las exportaciones e importaciones de servicios comerciales se definen como la proporción de los servicios comerciales en las exportaciones e importaciones mundiales de esta categoría, la OMC utiliza las estadísticas de la balanza de pagos para medir las corrientes comerciales (OMC, 2015). Este rubro se toma en cuenta a partir de los exámenes de la Ayuda para el Comercio del año 2009.

Estos servicios se dividen en las siguientes categorías: servicios comerciales, viajes, otros servicios comerciales, transporte, servicios relacionados con las mercancías, y servicios de tecnologías de la información y las comunicaciones (TIC). En el año 2016, las exportaciones de servicios comerciales aumentaron un $0,4 \%$, donde el sector de las TIC se posicionó como el más dinámico; asimismo aumentaron los ingresos por concepto de servicios de viajes un $2 \%$ lo que provoca un aumento del $3,9 \%$ de llegadas de turistas internacionales de todo el mundo y el aumento de las exportaciones asiáticas de servicios de viajes. El rubro con el crecimiento más bajo fue para transportes, con una disminución de 853.000 millones de dólares EE.UU. (-4\%), esto como causa de la contracción del comercio en los sectores marítimo y aéreo, por el estancamiento económico y el exceso de capacidad (OMC, s.f.).

Para el caso de América Latina y el Caribe, las exportaciones de servicios comerciales aumentaron un 6,3\% superando el incremento de 1,9\% en el año 2016 y los servicios de tecnologías de la información son los que más contribuyeron a este crecimiento. Los principales exportadores en la región fueron: México con un 10,5\%, seguido de Sudamérica con un 5,8\% y Centroamérica con un 5,7\% (UNCTAD, 2018).

En Guatemala, el sector servicios agrupa a exportadores de servicios de turismo sostenible, turismo de salud y bienestar, software, laboratorios, industria creativa y otros servicios para la exportación que, en conjunto, crean una oferta creativa, hospitalaria, tecnificada y profesional reconocida por la calidad. Este sector ha presentado un crecimiento acelerado cada año, y el país se ha posicionado como líder en la tercerización de servicios en la región, las exportaciones generan $\$ 1.000$ millones anuales y 1.000 empleos directos e indirectos. Los principales destinos de exportación son Centroamérica, México, Estados Unidos, Europa y Sudamérica (AGROEXPORT, s.f.). 
En la Figura 14 se muestra el registro más bajo de exportaciones que fue el año 2004, con un valor de $\$ 1.014 .800 .000$ a precios actuales y el más alto en el año 2017 con un total de $\$ 2.771 .600 .000$ a precios actuales (Figura 13). La tasa de variación del comercio de servicios para Guatemala en el periodo de 2010 a 2017 es de un 3\%. Los principales servicios exportados fueron los relacionados con las TIC con un $44,1 \%$ y en segundo lugar otros servicios empresariales con un $43,7 \%$ (UNCTAD, 2018).

\section{Figura 14. Guatemala. Exportaciones de servicios comerciales (US\$ a precios actuales)}

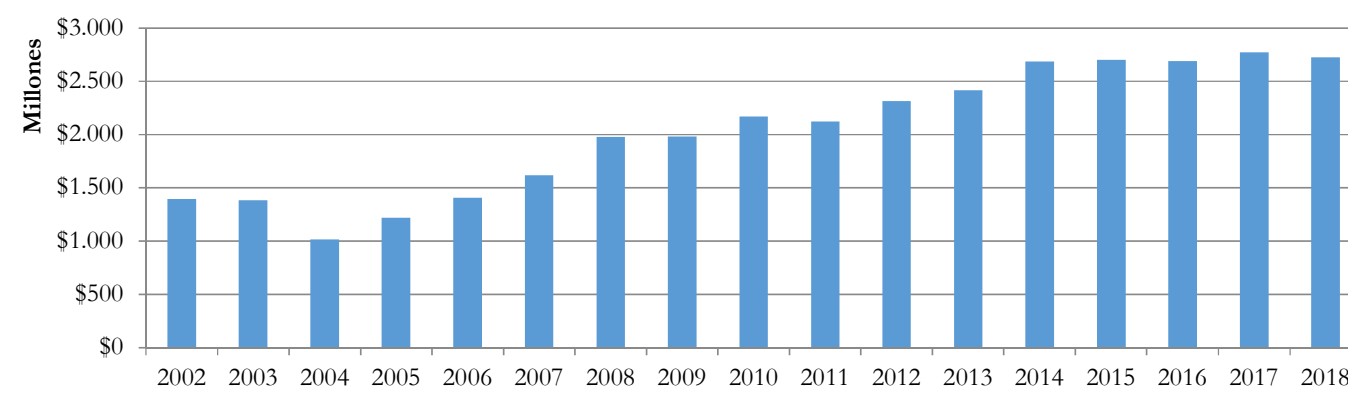

Fuente: Elaboración propia con datos del Banco Mundial (2019)

La demanda internacional ha impulsado la búsqueda de soluciones que mejoren y faciliten las experiencias del público consumidor de servicios especializados y, por ende, que los grupos proveedores de los servicios se fortalezcan con el desarrollo del capital humano en tecnologías para, así, mejorar la capacidad competitiva y lograr sobrepasar las expectativas de su clientela. Aunado a esto, el compromiso, la dedicación y la calidez se convierten en factores de atracción de la inversión y desarrollo de nuevas empresas con distintos tipos de servicios, de esta manera se amplía la oferta exportable del país (AGROEXPORT, s.f.).

Para el caso de Guatemala, en el rubro de importaciones de servicios comerciales, mantiene un crecimiento constante a lo largo de los años, donde el valor más bajo fue en el 2002 con 1.018.238.544 USD y el más alto en el año 2018 con 3.414.900.000 USD (ver figura 15). Esto representa una variación de 4\% en la importación de servicios comerciales durante el periodo de 2010 a 2017 (UNCTAD, 2018).

\section{Figura 15. Guatemala. Importaciones de servicios comerciales (US\$ a precios actuales)}

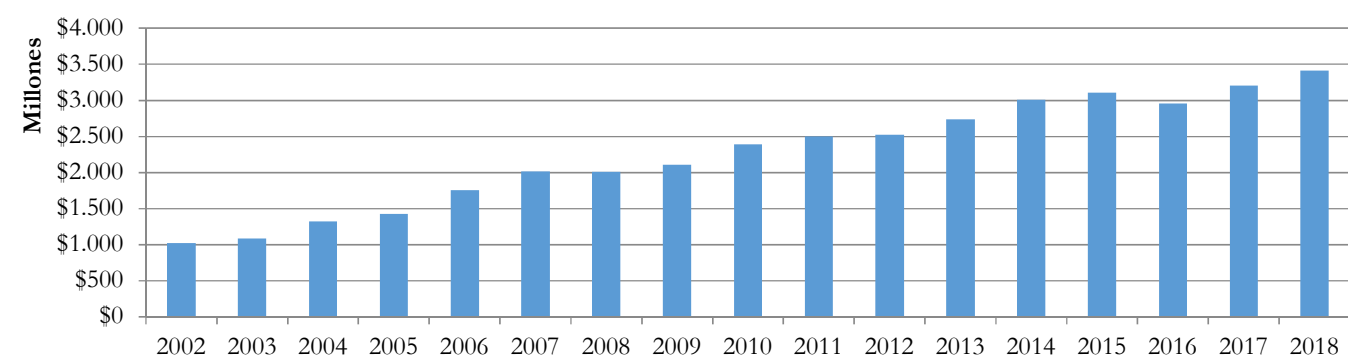

Fuente: Elaboración propia con datos del Banco Mundial (2019)

En cuanto a las exportaciones hondureñas de servicios comerciales, el crecimiento más bajo lo registró en el año 2009 con 1.840.858.465 USD y el más alto fue en el 2015 con 2.896.890.421 USD (Figura 16). Honduras presenta una tasa de variación de $4 \%$ en las exportaciones de servicios comerciales durante el periodo 2010-2017. Para 2019 las principales exportaciones de servicios 
Kendall López - Ingrid Arroyo - Cristel Avendaño - Yoselin Ramírez

Línea Base Situacional de la Ayuda para el Comercio en Guatemala y Honduras

comerciales se concentraron en los rubros de TIC con un 64,7\%, seguido de otros servicios empresariales con un $32,7 \%$ (UNCTAD, 2018).

Figura 16. Honduras. Exportaciones de servicios comerciales (US\$ a precios actuales)

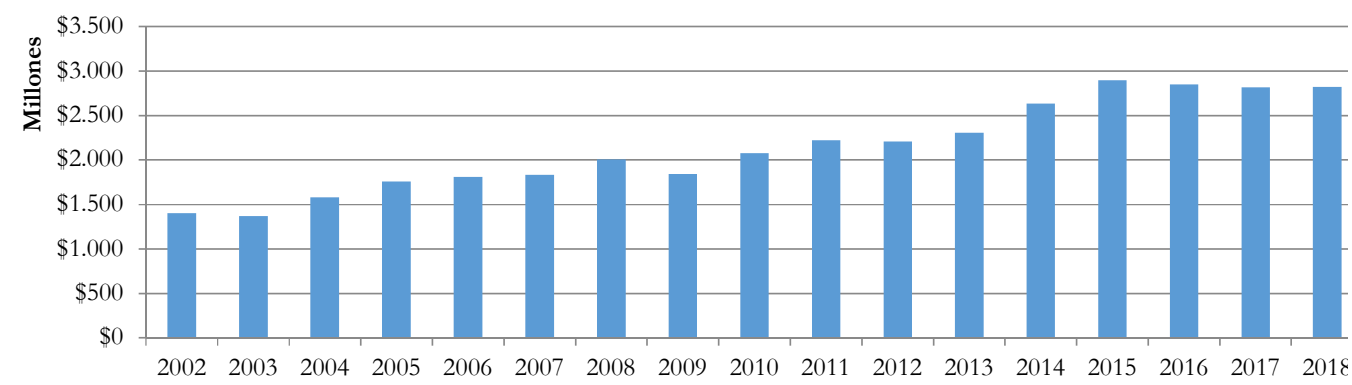

Fuente: Elaboración propia con datos del Banco Mundial (2019)

Con respecto a las importaciones de servicios comerciales, Honduras, a partir del año 2009, ha mantenido un constante crecimiento, dónde 2009 alcanzó el valor más bajo con 942.374.279 USD y el más alto en 2018 con 2.113.113.172 USD (Figura 17). La tasa de variación de Honduras en las importaciones de servicios comerciales durante el periodo 2010-2017 fue de 7\% (UNCTAD, 2018).

Figura 17. Honduras. Importaciones de servicios comerciales (US\$ a precios actuales)

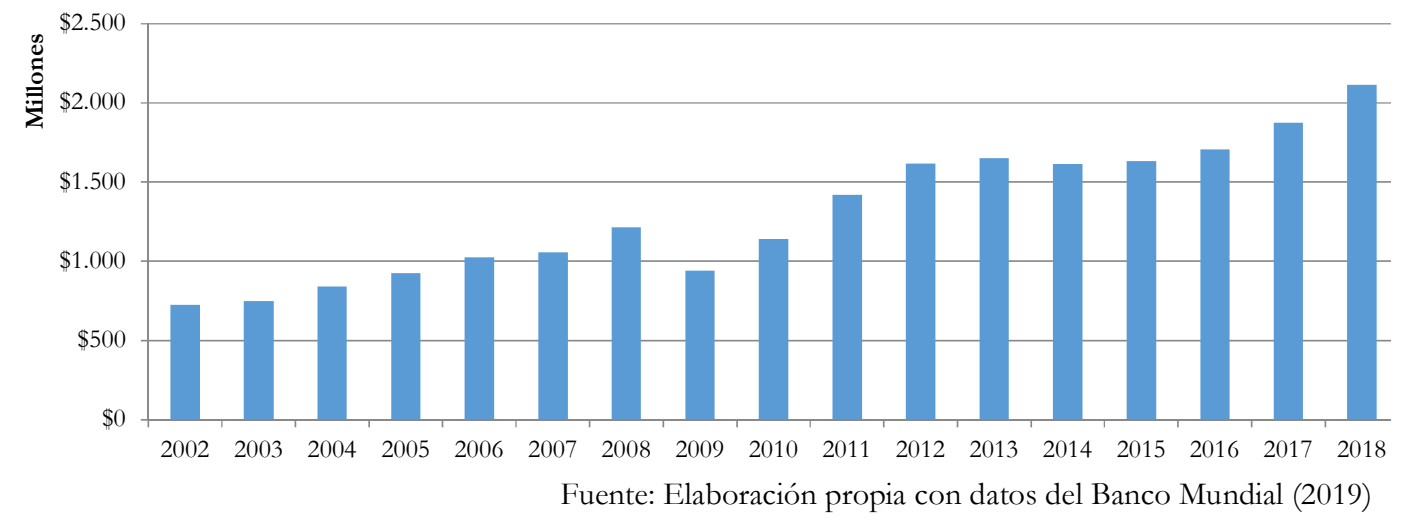

\section{Diversificación de mercados}

La diversificación de mercados se toma en cuenta en los exámenes de la Ayuda para el Comercio a partir del año 2015 y se entiende como el número de mercados de exportación e importación que representa la diversificación de los mercados. Además, en este rubro, se utiliza el índice de concentración Herfindahl-Hirschman (IHH) que ayuda a medir el nivel de concentración en relación con sus productos y mercados. Un IHH cercano a cero indica que el comercio de ese país está diversificado respecto de sus mercados y los resultados cercanos a uno indican que el comercio está centrado en unos pocos mercados (OMC, 2015).

Para el caso de Guatemala, el IHH que en el año 2013 fue de un máximo de 223 mercados de exportación e importación, concentraba 134 mercados de exportación y 108 mercados de importación, con un IHH de 0,173 en el caso de los mercados de exportación y 0,163 en el mercado de importación, lo que significa un mercado poco diversificado. Por su parte Honduras, de un máximo de 223 mercados de exportación e importación en el 2013 concentraba 99 mercados de 
exportación y 103 mercados de importación, con un IHH de 0,224 de mercados de exportación y 0,188 en mercados de importación; lo que supone que sus mercados están poco diversificados y concentrados en pocos mercados.

Ya para el periodo de 2015 a 2017 el número máximo de mercados de exportación e importación era de 237. En este caso, Guatemala, para el primer año concentraba 132 mercados de exportación y 115 mercados de importación, lo que generaba un IHH de 0,148 en los mercados de exportación y 0,166 en los mercados de importación; esto es, continúa con una diversificación baja de los mercados. En 2017 concentró 130 mercados de exportación y 114 mercados de importación con un IHH de 0,146 para los mercados de exportación y 0,177 en los mercados de exportación: prosigue con una diversificación baja.

Para el caso de Honduras, en 2015 concentró 94 mercados de exportación y 106 mercados de importación con un IHH de 0,216 en los mercados de exportación y 0,791 en los mercados de importación, lo cual representa una diversificación baja. Para el año 2017 agrupó 106 mercados de exportación y 127 mercados de importación con un IHH de 0.192 en los mercados de exportación y 0,16 en los mercados de importación.

Tabla 2. Diversificación de mercados de exportación e importación en Guatemala y Honduras. Período 2013, 2015 y 2017

\begin{tabular}{|c|c|c|c|c|c|c|}
\hline \multirow[b]{2}{*}{ Indicador } & \multicolumn{2}{|c|}{ Examen 2015} & \multicolumn{2}{|c|}{ Examen 2017} & \multicolumn{2}{|c|}{ Examen 2019} \\
\hline & $\begin{array}{l}\text { Guatemala } \\
\text { (2013) }\end{array}$ & $\begin{array}{l}\text { Honduras } \\
\text { (2013) }\end{array}$ & $\begin{array}{l}\text { Guatemala } \\
\text { (2015) }\end{array}$ & $\begin{array}{l}\text { Honduras } \\
\text { (2015) }\end{array}$ & $\begin{array}{l}\text { Guatemala } \\
\text { (2017) }\end{array}$ & $\begin{array}{l}\text { Honduras } \\
\text { (2017) }\end{array}$ \\
\hline \multicolumn{7}{|l|}{ a. Número de mercados } \\
\hline de exportación & 134 & 99 & 132 & 94 & 130 & 106 \\
\hline $\begin{array}{l}\text { b. Número de mercados } \\
\text { de importación }\end{array}$ & \multicolumn{5}{|c|}{ de importación } & 127 \\
\hline \multicolumn{7}{|l|}{$\begin{array}{l}\text { de los mercados de } \\
\text { exportación }\end{array}$} \\
\hline $\begin{array}{l}\text { de los mercados de } \\
\text { importación }\end{array}$ & 0,163 & 0,188 & 0,166 & 0,791 & 0,177 & 0,16 \\
\hline Año & \multicolumn{6}{|c|}{ Unidades de medida } \\
\hline \multirow{4}{*}{2013} & \multicolumn{6}{|c|}{ a. Número de mercados de exportación (Máx. 223) } \\
\hline & \multicolumn{6}{|c|}{ b. Número de mercados de importación (Máx. 223) } \\
\hline & \multirow{2}{*}{\multicolumn{6}{|c|}{$\begin{array}{l}\text { c. IHH (0 a 1) } \\
\text { d. IHH (0 a } 1)\end{array}$}} \\
\hline & & & & & & \\
\hline \multirow{4}{*}{2015 y 2017} & \multicolumn{6}{|c|}{ a. Número de mercados de exportación (Máx. 237) } \\
\hline & \multirow{2}{*}{\multicolumn{6}{|c|}{$\begin{array}{l}\text { b. Número de mercados de importación (Máx. 237) } \\
\text { c. IHH (0 a 1) }\end{array}$}} \\
\hline & & & & & & \\
\hline & d. IHH (0 a 1) & & & & & \\
\hline
\end{tabular}

Fuente: OMC. 2015, 2017 y 2019. Exámenes globales de la Ayuda para el Comercio. Elaboración propia.

Por ende, a pesar de que las economías de Guatemala y Honduras han experimentado mejoras respecto la concentración de mercados de exportación e importación, la diversificación de su mercado de servicios continúa siendo baja. Es decir, sus ingresos se concentran en un grupo muy pequeño de servicios y países, lo que provoca una menor estabilidad del crecimiento económico en este rubro.

Es así como los indicadores comerciales evidencian la necesidad que tienen las economías centroamericanas de invertir, en mayor medida, en el sector de servicios para que puedan ser más 
Kendall López - Ingrid Arroyo - Cristel Avendaño - Yoselin Ramírez

Línea Base Situacional de la Ayuda para el Comercio en Guatemala y Honduras

competitivos a nivel internacional, pues actualmente no disponen de una oferta amplia y diversificada de los servicios, lo que, en consecuencia, provoca una participación en el intercambio comercial escasa.

\section{Contextualización de los indicadores de desarrollo en Guatemala y Honduras}

Los indicadores de financiación del desarrollo son utilizados por la OMC para medir el impacto a largo plazo de la iniciativa en materia de desarrollo que le permita aumentar su participación en el comercio internacional (OMC, 2016). En el presente apartado se describe el desarrollo de las economías de Guatemala y Honduras a partir del indicador de asistencia oficial al desarrollo (AOD), el cual permite medir el desarrollo económico de los países.

\section{Asistencia oficial para el desarrollo}

La Figura 18 muestra la evolución de la AOD a lo largo de los años de los países en estudio, Guatemala y Honduras. En donde Guatemala, ha recibido un total aproximado de \$5.706.973.995 USD de AOD en los últimos 15 años. De estos, el año con el aporte más bajo se registró en 2016 con solo un $0,40 \%$, lo que corresponde a $\$ 268.625 .013$ USD de AOD neta, mientras que 2006 registró el ingreso más alto con un 1,64\%, equivalente a \$484.633.929 USD de AOD neta.

En lo que respecta a Honduras, ha recibido un total aproximado de AOD de \$ 8.685.882.794 USD en el mismo periodo. En el año 2004 es cuando registra un mayor aporte de AOD con un 7,88\%, lo que equivale a $\$ 655.771 .226$ USD netos y el menor aporte se registra en 2016 con un 2,06\% lo que equivale a $\$ 413.214 .223$ USD. Comparando la financiación externa recibida por ambos países en el mismo lapso se evidencia que Honduras es el país que más recibe este beneficio.

\section{Figura 18. Guatemala y Honduras. Ayuda Oficial al Desarrollo (AOD) neta recibida (\% del INB)}

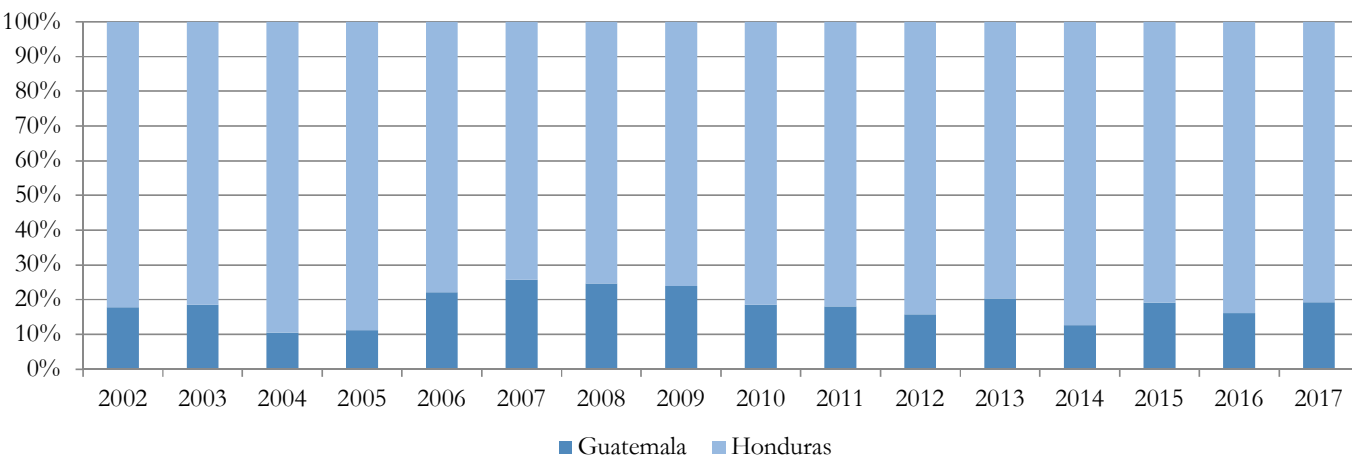

Fuente: Elaboración propia con datos del Banco Mundial (2019).

La OCDE es un agente importante en este tema, ya que impulsa la cooperación entre la OMC y la OCDE en áreas como agricultura, subvenciones a la exportación y subvenciones a la pesca (OMC, s.f.). Asimismo, ambas entidades mantienen cooperación en materia de asistencia técnica. En el año 2002 crearon una base de datos que "consolida la información relativa a los compromisos de ayuda relacionada con el comercio contraídos en la esfera de la creación de capacidad y asistencia técnica" (OMC, s.f.). Esta base de datos ya no existe, debido a que los miembros de la OMC han decidido utilizar el sistema de notificación de los países acreedores (CRS por sus siglas en inglés) para supervisar la Ayuda. 
Por otra parte, la OCDE colabora en vigilar la aplicación de la Ayuda, en los países receptores, proporcionando datos que muestren una visión general de las corrientes de Ayuda para el Comercio. Así, tanto la OMC como la OCDE trabajan de manera conjunta para elaborar el marco de vigilancia de la iniciativa, que permita definir la manera más oportuna y correcta de apoyar a los países en desarrollo y las capacidades en infraestructura vinculadas a las recomendaciones del Equipo de Trabajo especial de la OMC (OMC, s.f.).

\section{Estructura económica}

La estructura económica se define como aquel "desarrollo de la estructura económica de un país reflejado en la proporción que tiene la agricultura, la industria y los servicios en el Producto Interno Bruto (PIB)" (OMC, 2015, p. 325). De este modo, debido a que el objetivo central de esta investigación se concentra en la explicación del desarrollo del sector servicios en Guatemala y Honduras, a continuación, se explica la estructura económica de estos países desde el punto de vista de la proporción que ocupan los servicios en su economía.

Para el caso de Guatemala, los servicios han mantenido un crecimiento constante en la proporción del PIB desde el año 2015, concentra los servicios en el 2018 en 63,8\% del PIB. El crecimiento más grande de los servicios en el PIB fue de 29,9\% en el periodo de 2011 al 2015 y la mayor caída fue de $30,2 \%$ en el periodo de 2007 al 2011, donde pasó de representar el 60\% del PIB en el año 2007 a tan sólo el 29,8\% en el año 2011.

\section{Figura 19. Proporción del sector servicios en el PIB de Guatemala}

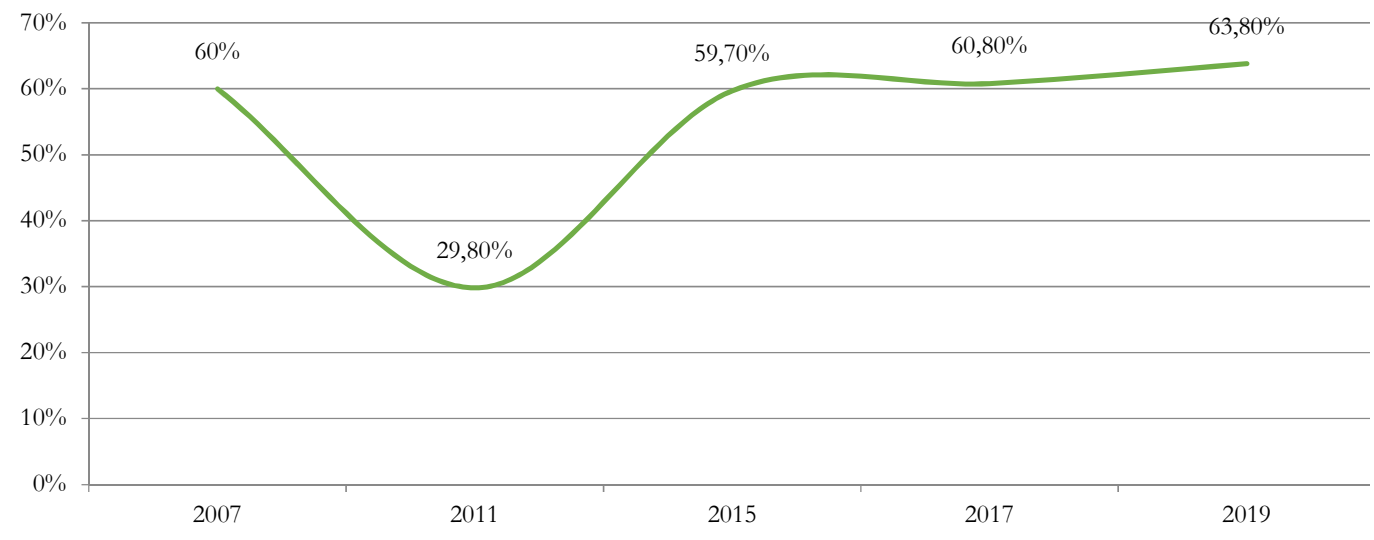

Fuente: Elaboración propia con datos de la OMC (2009,2011, 2015, 2017 y 2019).

Por el contrario, el sector servicios de Honduras mantiene una constante desaceleración en la participación del crecimiento económico de su país, ya que desde el año 2015 mantiene un promedio de decrecimiento de $1,15 \%$ (Figura 20). 
Kendall López - Ingrid Arroyo - Cristel Avendaño - Yoselin Ramírez

Línea Base Situacional de la Ayuda para el Comercio en Guatemala y Honduras

\section{Figura 20. Proporción del sector servicios en Honduras}

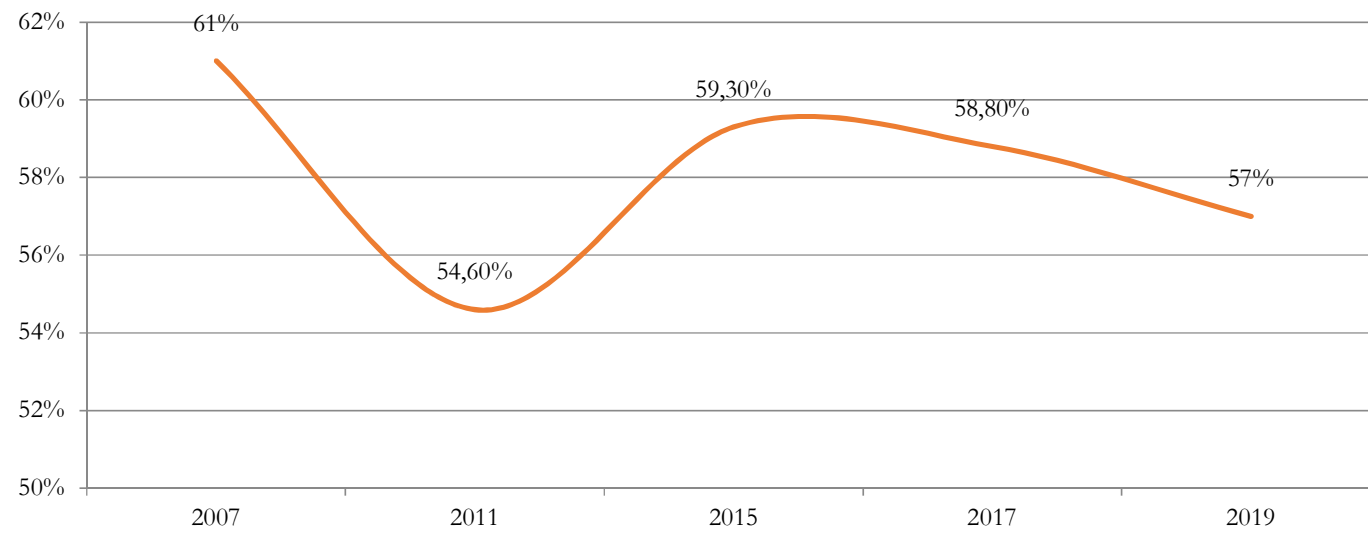

Fuente: Elaboración propia con datos de la OMC (2009,2011, 2015, 2017 y 2019).

En síntesis, comparando la estructura de servicios de ambos países, Honduras es el que presenta una desaceleración mayor en su economía. Resulta difícil ver la evolución de este sector en las economías en estudio, debido a que no hay mayor información sobre su comportamiento. Sin embargo, aunado a los resultados de los componentes e indicadores anteriores se concluye que ambos países deben trabajar en fortalecer sus economías para lograr una mayor diversificación, desarrollo y fortalecimiento del sector servicios, para así poder competir a nivel internacional.

\section{Conclusiones}

La implementación de la Ayuda para el Comercio en Guatemala y Honduras se realiza desde el primer examen en el 2007 hasta el último examen global en 2019. En dicho monitoreo y vigilancia se observa que durante el periodo 2006 al 2017, Estados Unidos se posiciona como el principal donante para Honduras, mientras que Japón es el principal donante para Guatemala. Respecto de la recepción de ayuda, Honduras es el mayor receptor durante el período 2002-2017, específicamente en el año 2004, mientras Guatemala lo fue en 2007.

En cuanto a las áreas en que se enfoca la iniciativa de AFT, Guatemala destina la mayor cantidad de desembolsos al sector agrícola, de transportes y almacenajes. Se desatienden las necesidades para desarrollo de los servicios que requieren mejoras constantes en temas de infraestructura vial y de preparación tecnológica y conectividad, suministros eléctricos, costos y tiempos para comercializar. Lo cual obstaculiza la competitividad del sector y, por ende, el crecimiento económico del país. Este es el mismo escenario para Honduras, en donde en el 2009 los desembolsos se destinaban a la capacidad productiva (agricultura, silvicultura y pesca) y los siguientes años cambia hacia los sectores de transporte y almacenaje. De este modo, a pesar de las deficiencias que presentan, tanto Guatemala como Honduras no tienen un enfoque al desarrollo competitivo del sector terciario, pese a ser uno de los sectores de mayor auge y de posibilidades de crecimiento en cada uno de los respectivos países. El cual incrementa cada vez más su participación en el comercio internacional y su uso intensivo de mano de obra y conocimiento.

Por otra parte, si bien es hasta el examen global 2017 que el indicador de conectividad de Internet se incorpora en el monitoreo de los países de la región de Centroamérica. Es ahí, donde se observa que las economías centroamericanas han mejorado en temas de conectividad, pero aún continúan por 
debajo de los niveles internacionales, lo cual representa un reto para países como Guatemala y Honduras.

Existe un progreso entre el 2011 al 2018 en materia de tiempos de exportación e importación en ambos países, con un retroceso en el año 2016 y seguido de un estancamiento. Sin embargo, es Guatemala quien presenta mayores retos en cuanto a los costos del comercio. Asimismo, se observa que el aspecto que más afecta el desempeño logístico es la infraestructura (la calidad de la infraestructura del comercio y transporte); aunado a un nivel de ineficacia de los procedimientos de despacho aduanero y en frontera; este, en conjunto con la baja calidad de infraestructura; lo cuales se convierten en la principal razón de rezago, ya que la ineficiencia incrementa los costos y reduce la predictibilidad del movimiento de cargas internacionales por vías terrestres.

Finalmente, como es característico de las economías latinoamericanas, se presenta también un déficit en cuanto a las importaciones de servicios comerciales en contraste de las exportaciones de servicios comerciales. Igualmente, si bien las economías de Guatemala y Honduras han experimentado mejoras en la concentración de mercados de exportación e importación, la diversificación de su mercado de servicios continúa siendo baja. Es así que, comparando la estructura de servicios de ambos países, Honduras es el que presenta una desaceleración mayor en su economía.

\section{Referencias}

AGEXPORT Guatemala. (s.f.). Trámites de importación y exportación. Disponible en https://export.com.gt/publico/tramites-de-importacion-y-exportacion

Alonso, J. \& Glennie, J. (2016). ¿Qué es cooperación para el desarrollo? Disponible en http://archive.ipu.org/splz-e/nairobi16/policy-brief-sp.pdf

Banco Interamericano de Desarrollo (2013). Diagnóstico sobre el desempeño de los puertos y estudio de conectividad portuaria en Belice, Centroamérica y República Dominicana. Disponible en $\quad \underline{\text { https://publications.iadb.org/es/publicacion/16684/diagnostico-sobre-el- }}$ desempeno-de-los-puertos-y-estudio-de-conectividad-portuaria

Banco Mundial (s.f.). Tiempo necesario para registrar una propiedad (días), Honduras. Datos, Proyecto Doing Business. Disponible en https://datos.bancomundial.org/indicator/IC.PRP.DURS?locations $=\mathrm{HN}$

Banco Mundial (2015). Comercio transfronterizo. Metodología, Doing Business. Disponible en https://espanol.doingbusiness.org/es/methodology/trading-across-borders

Banco Mundial (2019). Metodología del comercio transfronterizo. Disponible en https://www.doingbusiness.org/en/methodology/trading-across-borders

Barrera, J. (2018). Centroamérica ya tiene 22 millones de usuarios de internet. E\&N. Disponible en https://www.estrategiaynegocios.net/lasclavesdeldia/1154931330/centroam $\% \mathrm{C} 3 \%$ A9rica-ya-tiene-22-millones-de-usuarios-en-internet

Case, K. \& Fair, R. (2008). Principios de Macroeconomía. Pearson Education. Octava edición. México.

CENTREX. (2017). Documentos. Centro de Trámites de Exportación. Disponible en https://seceh.centrex.hn/

CENTREX. (2017). Trámites. Centro de Trámites de Exportación. Disponible en https://seceh.centrex.hn/

Consejo Nacional de Competitividad. (2018). Índice de Desempeño Logístico 2018. Disponible en http://www.competitividad.org.do/wpcontent/uploads/2018/07/\%C3\%8Dndice-deDesempe $\%$ C3\%B1o-Log\%C3\%ADstico-2018-Final.pdf

Daniels, J.; Radebaugh, H.; Sullivan, D. (2010). Negocios Internacionales. Pearson Education. Decimosegunda edición. México.

Flores, A. (2017). Honduras: ¿centro logístico de Centroamérica? É Revistas, Logística. Disponible en http://www.logisticamx.enfasis.com/articulos/77766-hondurascentro-logisticocentroamerica- 
Kendall López - Ingrid Arroyo - Cristel Avendaño - Yoselin Ramírez

Línea Base Situacional de la Ayuda para el Comercio en Guatemala y Honduras

Fundación para el desarrollo de Guatemala. (2016). Infraestructura para el Desarrollo. FUNDESA. Disponible en http://www.mejoremosguate.org/cms/content/files/publicaciones/MG_Revista Ed-16.pdf

Gobierno de la República de Honduras (2018). 2018: el año de los corredores del Pacífico, Occidente, Logístico, Turístico y Canal Seco. Disponible en https://presidencia.gob.hn/index.php/2018-01-11-0619-18/3511-2018-el-ano-delos-corredores-del-pacifico-occidente-logistico-turistico-ycanal-seco

Gobierno de la República de Honduras (2016). Plan Estratégico Empresa Nacional de Energía Eléctrica 2016-2020. Disponible en http://www.enee.hn/planificacion/2017/boletines/PEI\%20ENEE\%2020162020 dic 1 MRPV.pdf

González, R. (2011). Diferentes teorías del comercio Internacional. Disponible en http://vonhumboldt.org/paper/Blanco $\% 20 \% 20$ resumen $\% 20$ teorias $\% 20$ comercio $\% 20$ in ternacional.pdf

INFOCENTREX (2007). Requisitos para importar a paises de Centroamérica. Centro de Trámites de Exportación.

Disponible en https://www.centrex.gob.sv/scx html/INFOCENTREX\%20julio\%20sep.2007.pdf

Kotler, P. y Armstong, G. (2013). Fundamentos del marketing. Décimo primera edición. Pearson Education, México. ISBN: 978-607-32-1722-4

López, K. (2017). La OMC como régimen internacional de cooperación en materia de "Ayuda para el Comercio" en los países menos adelantados: Caso de Haití. Tesis de grado. Universidad Nacional, Costa Rica.

Martínez, P. (2006). El método de estudio de caso. Revista Pensamiento \& Gestión. Número 20. Pp.165-193. Universidad del Norte, Barranquilla Colombia. Disponible en https://www.redalyc.org/pdf/646/64602005.pdf

Melgar, J. (2016). Usuarios y Uso de Internet en Guatemala. Ilifebelt. Disponible en https://ilifebelt.com/usuarios-uso-internet-guatemala/2016/09/

Melgar, J. (2017). Brecha Digital en Centroamérica. ¿Cuántos tenemos acceso a internet? Ilifebelt. Disponible en https://ilifebelt.com/brecha-digital-centroamerica/2017/05/

MEM. (2017). Subsector eléctrico en Guatemala. Ministerio de Energía y Minas. Disponible en https://www.mem.gob.gt/wp-content/uploads/2015/06/SubsectorEl\%C $3 \% \mathrm{~A} 9 \mathrm{ctricoen}-\mathrm{Guatemala}$.pdf

MINECO. (s.f.). Plan Nacional de Facilitación del Comercio. Ministerio de Economía (MINECO), Gobierno de Guatemala. Disponible en https://www.mineco.gob.gt/plan-nacional-defacilitaci $\% \mathrm{C} 3 \% \mathrm{~B} 3 \mathrm{n}$-del-comercio

OMC (2015). Examen global de la Ayuda para el Comercio. Disponible en https://www.wto.org/spanish/res_s/booksp_s/aid4trade15_chap2_s.pdf

OMC (s.f.). Ayuda para el comercio. Disponible en https://www.wto.org/spanish/tratop s/devel s/a4t s/aid4trade s.htm

OMC (2016). Informe sobre el comercio mundial 2016. Disponible en https://www.wto.org/spanish/res s/booksp s/world trade report16 s.pdf

OMC (s.f.). Capitulo IV. Comercio de mercancías y comercio de servicios comerciales. Disponible en https://www.wto.org/spanish/res s/statis s/wts2017 s/WTO Chapter 04 s.pdf

OMC (s.f.). Examen global de la Ayuda para el Comercio. Disponible en https://www.wto.org/spanish/tratop_s/devel_s/a4t_s/aid4trade_s.htm

OMC (2009). Aid for Trade at a Glance 2009. Disponible en https://www.wto.org/english/res e/booksp e/aid4trade09 e.pdf

OMPI (2019). Índice Mundial de Innovación. Organización Mundial de la Propiedad Intelectual (OMPI). Disponible en https://www.wipo.int/global innovation index/es/2019/

Quintero, J \& Sánchez, J. (2006). La cadena de valor: Una herramienta de pensamiento estratégico. Disponible en https://www.redalyc.org/pdf/993/99318788001.pdf

Ramos, C. (2015). Los paradigmas de la investigación cientifica. Revista de Psicología. Universidad Femenina del Sagrado Corazón. Perú. Volumen 23 (1). Disponible en http://www.unife.edu.pe/publicaciones/revistas/psicologia/2015 1/Carlos Ramos.pdf 
Rodríguez, L. (2017). Tiempo de los trámites en aduanas de Honduras se reducirá a 5 días. El Heraldo. Disponible en https://www.elheraldo.hn/pais/1031701-466/tiempo-delostr\% $\%$ C3\%A1mites-en-aduanas-de-honduras-se-reducir $\% \mathrm{C} 3 \% \mathrm{~A} 1-\mathrm{a}-5$

Rodríguez, L. (2018). Los 9 sectores que más aportaron a la economía de Honduras. El Heraldo. Disponible en https://www.elheraldo.hn/economia/1179720-466/los-9-sectores-que-m\%C3\%A1saportaron-a-la-econom $\% \mathrm{C} 3 \% \mathrm{ADa}$-de-honduras

Ruiz, G. (2013). La Cadena de Valor. Disponible en https://mbaramiromamani.files.wordpress.com/2011/12/lectura-cadena-de-valor.pdf

Salvia, A. (2015). Heterogeneidad estructural, desigualdad económica y globalización en América Latina. Universidad Autónoma de Baja Mexicali, Baja California (México). Ediciones Once Ríos.

Sánchez, A. (2007). La productividad en el sector servicios: Un análisis económico aplicado. Universidad de Alcalá.

Disponible https://www.researchgate.net/publication/236942291 La productividad en el sector servicios Un analisis economico aplicado

Sazo, S. et all. (2011). Problemática Industrial en Guatemala. Disponible en http://webcache.googleusercontent.com/search?q=cache:j43sq12TZIJ:problemasusac.jimdo.com/app/download/5768295771/PROBLEMATICA\%2B INDUSTRIAL $\% 2 B E N \% 2 B G U A T E M A L A 2 . p d f \% 3 F t \% 3 D 1412481897+\& \mathrm{~cd}=1 \& \mathrm{khl}=\mathrm{es}$ $-419 \& \mathrm{ct}=\mathrm{clnk \& gl}=\mathrm{cr}$

UNCTAD. (2018). Comercio internacional de servicios en América Latina y el Caribe: Tendencias y perfiles. Disponible en http://mitagds.com/Estudio.pdf

Valenzuela, C \& Cruz, D. (2017). Estudio de caso sobre estrategia para promover la inclusión financiera de pequeños productores Honduras. CEPAL. Disponible en https://repositorio.cepal.org/bitstream/handle/11362/40912/1/S1700681 es.pdf

WEF. (2018). The Global Competitiveness Report 2018. World Economic Forum (WEF). Disponible en https://es.weforum.org/reports/the-global-competitveness-report-2018

WEF. (2019). The Global Competitiveness Report 2019. World Economic Forum (WEF). Disponible en http://www3.weforum.org/docs/WEF TheGlobalCompetitivenessReport2019.pdf

\section{(c) (i) ()}

Open Access This article is licensed under a Creative Commons Attribution-Non Commercial 4.0 International License, which permits the use, adaption and sharing as long as you give appropriate credit to the original author(s) and the source. The images or other third party material in this article are included in the article's Creative Commons license, unless indicated otherwise in a credit line to the material. If materials are not included in the article's Creative Commons license and your intended use is not permitted by statutory regulation or exceeds the permitted use, you will need to obtain permission directly from the copyright holder.

To view a copy of this license, visit http://creativecommons.org/licenses/by-nc/4.0/.

(C) The Author(s) 2021. 